\title{
FAT CHAT: AN EXPLORATION OF OBESITY DISCOURSES IN CANADIAN MEDIA AND THEIR IMPACTS ON SOCIAL WORK
}

By

Samantha Abel, BSW, Ryerson University, 2012

\author{
An MRP \\ presented to Ryerson University \\ in partial fulfillment of the \\ requirements for the degree of \\ Master of Social Work \\ in the Program of \\ Social Work
}

Toronto, Ontario, Canada, 2014

(C) Samantha Abel 2014 


\section{AUTHOR'S DECLARATION FOR ELECTRONIC SUBMISSION OF A MRP}

I hereby declare that I am the sole author of this MRP. This is a true copy of the MRP, including any required final revisions.

I authorize Ryerson University to lend this MRP to other institutions or individuals for the purpose of scholarly research

I further authorize Ryerson University to reproduce this MRP by photocopying or by other means, in total or in part, at the request of other institutions or individuals for the purpose of scholarly research.

I understand that my MRP may be made electronically available to the public. 


\begin{abstract}
Fat Chat: An exploration of obesity discourses in Canadian media and their impacts on social work

Master of Social Work, 2014

Samantha Abel

Program of Social Work, Ryerson University
\end{abstract}

This Major Research Paper conducted a critical discourse analysis of Canadian Press articles focused on obesity. This research sought to understand how the articles constructed obesity, what discourses were operating, and what power relations were at play. The three main discourses that shaped the articles were mother blame, the medical model, and economics. They became evident through photographs, language used, gendered power relations, medicalized understandings of health and solutions to obesity, and who was profiting or benefitting from these understandings and solutions. Social work practitioners and educators need to consider these discourses when conceptualizing obesity, and strive to contextualize individual experiences of fatness within broader structural and systemic power relations. Social workers also need to be cautious about reproducing oppressive anti-obesity practices, social work is a profession that has historically been an agent of social control and discipline. 


\section{ACKNOWLEDGEMENTS}

I am grateful to all the Ryerson professors who have supported me during this journey. Especially my MRP supervisor Lisa Barnoff, who answers all my hard questions, and May Friedman, who encouraged me to continue.

I would like to thank Rosie and J.B. for keeping me grounded.

I would like to acknowledge my parents, who have put up with a lot of griping about this process.

Finally, I don't have enough words to thank Trevor, who shouldered the incredible burden of being the partner of a graduate student with grace, generosity, and love. I would not have made it through without you, and I am ready to clean my papers and books off our couch so you can sit on it for the first time in a year. 


\section{DEDICATION}

To all the Headless Fatties. I see you. 


\section{TABLE OF CONTENTS}

$\begin{array}{ll}\text { Introduction } & 1\end{array}$

Theoretical Framework 5

$\begin{array}{ll}\text { Literature Review } & 15\end{array}$

Research Design/Methodology 36

Findings $\quad 43$

$\begin{array}{ll}\text { Discussion } & 63\end{array}$

$\begin{array}{ll}\text { Recommendations and Conclusion } & 77\end{array}$

Reference List $\quad 79$ 


\section{LIST OF FIGURES}

Figure 1: Michelle Obama puts arms out with children 46

Figure 2: Michelle Obama dances with children 46

Figure 3: Michelle Obama on Sesame Street 46

Figure 4: Hands with IV and hospital bracelet $\quad 52$

Figure 5: Doctor measuring waist $\quad 52$

Figure 6: Doctor holding stethoscope $\quad 52$

Figure 7: Doctor using stethoscope $\quad 53$

Figure 8: Surgeons perform weight-loss surgery 53

Figure 9: Alexis Shapiro getting wheeled into surgery 53

$\begin{array}{ll}\text { Figure 10: Man on airplane tries to buckle seatbelt } & 61\end{array}$

$\begin{array}{ll}\text { Figure 11: Man in airplane seat } & 61\end{array}$

Figure 12: Half person on a scale, half airplane $\quad 62$

$\begin{array}{ll}\text { Figure 13: Woman in blue dress walking } & 68\end{array}$

$\begin{array}{ll}\text { Figure 14: Woman in pink shirt sitting } & 68\end{array}$

$\begin{array}{ll}\text { Figure 15: Person in tan jacket and jeans } & 68\end{array}$

$\begin{array}{ll}\text { Figure 16: Two women talking } & 68\end{array}$

$\begin{array}{ll}\text { Figure 17: Person eating at a bench } & 68\end{array}$

$\begin{array}{ll}\text { Figure 18: Woman measures person } & 69\end{array}$ 
"Weight-based discrimination is a cradle-to-grave phenomenon" (Wann, 2009, p. xix).

"Fat bodies are invaded by comments, measured with hatred, pathologized by fear, and diagnosed by ignorance" (Hartley, 2001, p. 65).

\section{CHAPTER 1. INTRODUCTION}

Western society continually targets fatness and fat people (Wann, 2009). On an individual level, the experiences of fat stigma are debilitating and pervasive, affecting all areas of an individual's life. On a societal level, the "war on obesity" is a focal point for social policy, public health, education and a variety of other systems and structures. Anti-oppressive social workers are trained to consider individual experiences and contextualize these experiences within broader systems and structures (Friedman, 2012). Unfortunately, the discrimination and marginalization of fat people is under-theorized and under-researched by social work scholars.

This Major Research Paper (MRP) aims to begin a discussion of how discrimination against fat bodies is an important issue for anti-oppressive social work practitioners. My experiences in social work education and as an anti-oppressive practitioner have shown me that fatness is an area of silence. These silences, the way that body size is either ignored or tip-toed around, do not operate alone. They are coupled with an ongoing body policing and an acceptance of dominant health discourses that frame fat bodies in a negative light.

Social work discourses often parallel dominant health discourses. Social work is a profession that has historically been an agent of social control and moral regulation (Friedman, 2012). Though many social workers are critical of the "common-sense" logic that has led to appallingly oppressive practices and policies in the past, we are not making the links with how 
our profession is still implicated in these oppressive practices, especially when it comes to bodies that are considered deviant on the basis of size (Friedman, 2012).

With no body of social work research that focuses on fat, I aim to begin to fill this gap. My research utilizes a critical discourse analysis method to draw out common themes in Canadian Press articles that focus on obesity. In North America "the mainstream media has gone from mentioning the term "obesity" only sixty times per year in the early 1980s to five hundred times per year in 1990, to one thousand mentions in 1995, three thousand mentions in 2000, and seven thousand...in 2003" (Wann, 2009, p. xvii). Based on my own initial searches of the Canadian Press articles, those numbers are exponentially higher in 2013. A Google search of Canadian Press articles mentioning obesity in the past year yields 117000 articles. Examination of health-related media coverage reveals a society's hopes and concerns - how they are developed, how they play out over time, and how they link to larger political and social dynamics (Yang \& Southwell, 2004). The numbers indicate that obesity is a societal concern that is commanding exponentially growing media focus, which is why I have chosen media as the focus of my research project.

\section{A Note on Language}

For many people, fat is not a simple descriptor. It is associated with many negative attributes such as being disgusting, lazy, ignorant, smelly, unattractive, undisciplined, gluttonous, unhealthy, sedentary, and much more (Harding \& Kirby, 2009). My body is fat. The medical and scientific standards that I challenge in this research project, would define me as fat, as "obese". Much more importantly though, I define myself as fat. My experiences have and continue to be shaped by what it is like for me to move through the world as a fat person. My fat body has 
caused me to be harassed, bullied, and excluded in ways that tangibly demonstrate the disgust that society at large holds for my body type and others like it.

It was not so long ago that I would have been devastated at the association between my body and the word fat. My journey to fat activism and fat acceptance has strongly relied on the reclamation of the word fat. Today when I use fat comfortably to describe myself, people are often uncomfortable and they respond by saying that I am not fat. What these people usually mean is that they don't associate me with any of the negative attributes that our society links to fat bodies. Reclaiming the word fat has been a powerful way for me to create a political space to challenge these associations and to begin to divorce the word fat from all the unquestioned negativity it is loaded with.

It is important to note that though I choose to define myself as fat, fatness is not a category that is static. Fatness can be slippery, fluid, changing, and difficult to pin down. My body interacts with my gender, my age, my ability, my race and all other aspects of social location. Definitions of fatness can differ based on other aspects of identity. Fatness also exists on a spectrum, and I would consider myself to be what people in fat acceptance/activism circles refer to as a "smaller fat". Having a smaller fat body means it is important for me not only to name my fat experience, but to be able to see the ways in which being a smaller fat afford me privilege.

"Overweight" implies that there is a single, objectively correct weight for every human body (Harding \& Kirby, 2009). "Obesity" has officially been classified as a disease by the American Medical Association (“American Medical Association”, 2013). Overweight and obese are both categories on the Body Mass Index (BMI), a tool I will be discussing further in future chapters. The BMI's purpose is to assess how much an individual's body weight departs from 
what is "normal" or "desirable" for a person of his or her height" ("Body Mass Index", 2013, para. 4). This wording automatically constructs in opposition transgressive bodies that are therefore "abnormal" and "undesirable." I reject these categorizations, and use fat purposefully and politically.

For the purposes of this MRP I will use fat, overweight, and obese to discuss bodies, reflecting the terms my sources are using. My search of Canadian Press articles will be using the keyword "obesity", because this is currently the dominant term for referring to fat bodies, and a preliminary search for the word "fat" did not yield results. 


\section{CHAPTER 2. THEORETICAL FRAMEWORK}

My theoretical framework is based on Foucauldian understandings of discourse and power, primarily his work in The History of Sexuality, Volumes I and II (Foucault, 1980; Foucault, 1985). Foucault's conceptualizations of morality inform my understanding of the ways fat bodies are seen as morally objectionable. Poole's (2007) work on recovery and public health discourses was also a substantial contributor to my theoretical framework and my understanding of the ways that health and health issues are framed. My theoretical framework was also informed by understandings about oppression and anti-oppressive practice, particularly those of Baines (2011) and Mulally (2002).

My understanding of power, health, morality, oppression, and anti-oppressive social work has resulted in a definition of discourse that is as follows:

Discourses about bodies are shifting ways of conveying, reinforcing, and reproducing ideas relating to the ideal neoliberal subject. These discourses utilize understandings of economy, pedagogy, medicine, morality, and law to define bodies in specific ways. Elements of certain discourses include ethos, food, exercise, clichés, sayings, slogans, vocabulary, photos, fears, conflicts, contradictions, blame, silences, what isn't said, what is assumed, rules, policies, programming, education, health, public, private, statistics, referencing, and transformation.

My discursive rules, which are shaped by my individual lens and govern how I will interpret the data, should be transparent entering this research process, and they are as follows:

1. Fatphobia is a legitimate form of oppression

2. Being fat is political

3. Fatness exists on a spectrum 
4. Body positivity is important

5. Not all fat people are unhealthy, and not all thin people are healthy

6. What we perceive about another person's health does not give us the right to be disrespectful or cruel to that person

7. The hatred of fat bodies causes many more negative health effects than simply being fat ever could

The increasing focus on fat bodies is fraught with power relations. The framing of fatness as a public health crisis, as a "war" that needs to be fought, as a body that is both silenced and made hypervisible, is not "normal", "natural", or "common sense", it is the result of a newer regime of discourses (Foucault, 1980). Fatness has historically functioned in relation to dominant discourses during various time periods. "There were times and places where fatness was embraced, celebrated, viewed as being aesthetically pleasing, and sexy" (Parsons, 2012, p. 197). The politics of fatness and thinness are historically and culturally bound, with different body types having value at various points (Parsons, 2012). The difference between the historical and cultural valuing of fatness, and contemporary North American negative framings of fat bodies demonstrates that these discourses are not facts, they are elaborate social constructions. It is vital to understand this discursive fluidity because "most North Americans alive today have no memory of a time when thinness was not a national obsession, and thus have no choice but to regard this as normal" (Poulton, 1996, p. 17).

As mentioned in the introduction, I have experienced fat as an area of silence in education and practice; areas where things don't need to be said because they are assumed and because they function within a preconceived set of rules. 
Silence itself - the things one declines to say, or is forbidden to name, the discretion that is required between different speakers - is less the absolute limit of a discourse...than an element that functions alongside things said, with them and in relation to them within all over strategies...We must try to determine the different ways of not saying such things, how those who can and those who cannot speak of them are distributed, which type of discourse is authorized..." (Foucault, 1980, p. 27-28)

Bodies have been constrained to lead a discursive existence (Foucault, 1980). Fat discourses are shaped by the "manifold mechanisms which, in the areas of economy, pedagogy, medicine, and justice, incite, extract, distribute, and institutionalize" (Foucault, 1980, p. 33). There also exists a singular imperialism that compels everyone to transform their bodies. This imperialism is experienced differently depending on peoples' intersectional realities, for example, women may feel this pressure far more than men. Where there is desire and drive to be thin, to change the body so one achieves a body that is "normal", a power relation is already present (Foucault, 1980).

Foucault's (1980) discussion of the principle features of power is extremely relevant to fat oppression. The first feature is the negative relation. No positive connection is established between power and fat, resulting in rejection and exclusion (Foucault, 1980). Fat bodies are refused, the expectation is that they are concealed or masked (Foucault, 1980). Where fat and bodies are concerned, "power can 'do' nothing but say no to them; what it produces...is absences and gaps; it overlooks elements, introduces discontinuities, separates what is joined," like body and mind, "and marks off boundaries", for example, where the cut-off is between "normal" and "overweight" (Foucault, 1980, p. 83). The second feature is the insistence of the rule. Power essentially dictates its laws to bodies. Fatness is placed by power in a binary system of what is permitted and what is forbidden. Power prescribes an "order" for fatness that operates as a form of intelligibility (Foucault, 1980, p. 83). This relates to the spectrum of fatness, to be deciphered on the basis of its relation to the order. How close is a fat body to being thin? Power is enacted 
by laying down the rules, maintained by language and through the act of discourse (Foucault, 1980). These rules, language, and discourses are internalized, enacted, and exercised by people, systems, structures, and societies. The third feature is the cycle of prohibition. Power's objective is that fat renounce itself. Renounce yourself, declare yourself unhealthy, lose weight, or suffer the penalty of being supressed (Foucault, 1980). "Do not appear if you do not want to disappear. Your existence will be maintained only at the cost of your nullification" (Foucault, 1980, p. 84). Many fat activists have discussed how the fat body is only allowed to exist on the way to being thin (Cooper, 1997; Friedman, 2012; Kent, 2001; Mik-Meyer, 2010).

To put it bluntly, there is no such thing as a fat PERSON. The person is presumptively thin, and cruelly jailed in a fat body. The before-and-after scenario both consigns the fat body to an eternal past and makes it bear the full horror of embodiment, situating it as that which must be cast aside for the self to truly come into being. (Kent, 2001, p. 135)

Fat discourses are often intertwined with dominant discourses about health. Discourses on health emerge and gain widespread acceptance when they are in line with the dominant sociopolitical context in which they are produced (Poole, 2007). The ways that we speak about health are never about health alone (Poole, 2007). Health is attached to other interests and "professional, economic, political, cultural, and ideological" agendas (Robertson, 1998, in Poole, 2007, p. vii). Health discourses are reflexive categories, principles of classification, normative rules, and institutionalized types (Foucault, 1972). Poole (2007) urges us to question who is able/allowed to produce the obese body, where are these producers situated and what is their relationship to obesity? What is there to be gained through a dominant framing of obese bodies? How are the definitions of obesity to be used? What other explanations are negated by it? What do these definitions do? To what end? My research will speak to some of these questions.

Fatness is not only perceived as medically unhealthy, but morally unhealthy as well. Fat people are continuously constructed as morally inferior (Mik-Meyer, 2010). In The History of 
Sexuality, Volume II Foucault (1985) describes morality as, "a set of values and rules of action that are recommended to individuals through the intermediary of various prescriptive agencies..." (p. 25). I am interested in how articles put forth through the Canadian Press work together to function as a prescriptive agency, transmitting the rules of action to Canadians who consume the media. I am also interested in how those rules of action have been internalized by the authors of the articles. Morality also refers to the behaviour of individuals in relation to the rules and values that are recommended to them. Individuals are then judged on whether they comply more or less fully with these rules, the manner in which they obey or resist an interdiction or prescription (Foucault, 1985). I anticipate that I may also find examples of noncompliance, or resistance to dominant body discourses in the Canadian Press. I am interested in the "mode of subjugation", the way people establish their relationship to the rules about bodies, and how they recognize themselves as obligated to put the rules into practice, or the ways in which they resist (Foucault, 1985, p. 27).

Fat activists have also drawn attention to and challenged the ways that food itself is also moralized (Harding \& Kirby, 2009; Heyes, 2006; Wann, 2009). Food is loaded with meaning, a fat person eating a salad and a fat person eating a cheeseburger will be read in different ways, but all food whether "good" or "bad" carries the weight of moral significance. Over the past several decades, increasing scrutiny over the quality of what goes into people's mouths has been accompanied by something almost wholly new: the rise of universalizable moral codes based on food choices (Eberstadt, 2009). These ideas link to Foucault's (1980) discussion of how an action is not only moral in itself: it establishes a moral conduct that commits an individual to other actions always in conformity with values and rules. For example, dieting behaviour is not simply eating "good" food once; it is a pattern of eating through which an individual establishes 
themselves as partaking in a mode of being characteristic with an ethical subject (Foucault, 1985; Heyes, 2006).

The popularity of diets, cookbooks, and chef TV genres, as well as the proliferation of health food stores, and politically mandated nutritional breakdowns on restaurant menus speak to the paramount place food and food choices occupy in the modern consciousness (Eberstadt, 2009). Harding \& Kirby (2009) challenge the idea that there is such a thing as "good" food and "bad" food.

If you want an apple, you should eat the apple. If you want a cookie, you should eat the cookie. You absolutely should not eat the apple if you want the cookie, just because you are trying to be virtuous. There is no virtue in self-deprivation..." (p. 29).

Harding \& Kirby (2009) promote the Health At Every Size principle of intuitive eating, which means eating what feels right to you, when it feels right. External food plans and diets have divorced us from eating based on physical cues (Bacon \& Aphramor, 2011). "Eating when you are hungry, until you are full, has become a radical act” (Harding \& Kirby, 2009, p. 29).

My theoretical framework is also concerned with manifestations of oppression which connects to social work and anti-oppressive practice. Baines (2011) defines oppression as taking place when:

...a person acts or a policy is enacted unjustly against an individual (or group) because of their affiliation to a specific group. This includes depriving people of a way to make a fair living, to participate in all aspects of social life, or to experience basic freedoms and human rights. It also includes imposing belief systems, values, laws, and ways of life on other groups though peaceful or violent means. Oppression can be external...or internal, when groups start to believe and act as if the dominant belief system, values, and way of life are the best and exclusive reality. Internal oppression often involves self-hate, self-censorship, shame, and the disowning of individual and cultural realities. (p. 2)

I argue that people, policies, systems, and structures are oppressive towards fat bodies. Fat people suffer both from internal and external oppression. 
Baines (2011) advocates for more social justice-oriented approaches to social work. Social workers are ethically obligated to focus on the causes of social problems, and what can be done to address those causes rather than merely treating the victims (Baines, 2011). Social workers need to have a critical understanding of fatness, especially since we work alongside so many of the public health efforts to combat obesity. Social workers also work in community health settings and hospitals where fatness is seen as something that needs to be eradicated. Our profession is used as a tool in the war against obesity, and I have seen that many social workers do not think critically about this "fight". We are likely to see service users who are fat no matter what area of social work we practice in. We must equip ourselves to think critically about body size. Further, we need an intersectional approach to fatness. Fatness is closely associated with racialized populations and poverty and social workers need to consider intersecting forms of oppression that shape the fat experience (Ernsberger, 2009). Within current fat activist movements lie issues of power and intersectionality. Many of the leading activists in these movements are White and I wonder how racialized women would shape the issues differently, and why their voices are not often included. I think the Fat Acceptance and Health At Every Size movements are wonderful tools of resistance, but are they accessible to marginalized and racialized groups? How can we mobilize the fat community to fight against discrimination, when what we really seem to mean by the fat community are White, middle-class, academic women who have the power to shape the focus?

Anti-oppressive practice is about providing individual social work services, but it is also much broader. We have an obligation to clients, communities, and other social workers to understand that problems are linked to social inequality (Baines, 2011). Macro and micro social relations generate oppression. Macro-level social relations include social structures, social 
forces, and social processes such as capitalism, governments and their policies, religious and cultural institutions, international trade and financial bodies (Baines, 2011). Fat-specific examples of macro-level relations include government "obesity fighting" initiatives, a culturallyentrenched weight-loss movement, which is also tied to extremely high financial revenue, and insurance companies refusing health coverage to fat people.

Micro-level social relations include social norms, everyday practices, workplace specific policies, values, identities, and so-called common sense (Baines, 2011). Examples here include, having workplace uniforms that must be worn but not providing larger sizes, the common sense idea that fat is unhealthy, the celebrated identities of people who are heavily involved in personal fitness, the norm of most clothing stores only going up to a size 12, even though the average U.S. woman is a size 14, etc. Many acts of oppression at a personal level occur as aversive behaviour that emerges in everyday interactions between people (Mullaly, 2002). These actions can include avoiding eye contact, increasing physical distance, using gestures of defense and aversion, negative speech and tones of voice (Mullaly, 2002).

"Using the term 'social relations' highlights that these relations are organized and operated by people and can be halted or reorganized by them as well...they are not inevitable conditions of modern life or ones that we cannot change" (Baines, 2011, p. 5). Social workers' theoretical and practical development needs to be based on the struggles of marginalized people (Baines, 2011). However, it is important to note that fatness has no "fixed identity", fat people can be both oppressors and oppressed depending on a variety of factors (Mullaly, 2002). When we consider the marginalization of fat people, we must not consider fatness or the marginalization of fat bodies to be static concepts. The fat experience is dynamic and relational (Mullaly, 2002). Though the focus of this MRP is on fat issues, marginalization, and social work, 
it is overly simplistic to present fat oppression as being based solely on fatness. Fatness is not a singular group characteristic, although all fat people may be oppressed in some ways, there is a great diversity among fat people that will result in more or less oppression (Mullaly, 2002).

There is a need for social workers to begin questioning and developing new understandings of fatness that we can bring into our theories and practice. Social workers also have an ethical obligation to shift the individualized blame and shame away from fat clients and communities. We need to assist people with situating their bodily experiences within wider oppressive systems. Fat people often internalize what they see as their individual failure to be thin, and accept the stigma and discrimination they experience as their fault. It is extremely transformative to expose people to the fat activism and fat acceptance movements through online media, blogs, artistic means, photos, and social activism events.

I hope to promote a critical understanding of fatness in this MRP. I see a critical understanding of fatness as one that does not take all the "obesity epidemic" hype at face value. A critical understanding sees obesity as something that is socially constructed. A critical understanding of fatness goes deeper to bring forth ideas of intersectionality, oppression, marginalization, and stigma. A critical understanding sees fat people as human beings, and brings forth their voices and experiences into a discussion that somehow manages to both revolve around us and exclude us at the same time.

My MRP will study Canadian Press articles to begin to expose some of the prevailing social, political, and economic contexts within which fat bodies are produced, maintained, and reproduced (Robertson, 1998). Foucault's discussion of bio-power as a form of social control focuses on disciplinary practices such as education, medicine, creating categories, standards, and desires for what constitutes normal (Poole, 2007). "There is no power exercised without a series 
of aims and objectives" (Foucault, 1978, p. 95). I will be analyzing the aims and objectives of the Canadian Press articles discussing obesity. I hope to see micro-macro relations demonstrated in the articles, and bring in Baines (2011) to relate these to anti-oppressive social work practice. 


\section{CHAPTER 3. LITERATURE REVIEW}

Completing this literature review and deciding how to organize it was a challenge. Significantly, I noticed a consistent difference between secondary sources that looked more broadly at discursive conceptualizations of bodies and fatness, and primary research that looked at obesity issues. I will begin with broader literature that sets the stage for dominant understandings of fatness, and brings a critical lens to what is assumed. I will then narrow the focus and analyze primary research studies focused on various aspects of obesity and discrimination.

\section{Normative Bodies in Neoliberal Times}

Many people understand fat bodies as a significant departure from a "normal" physical body, as supported by both neoliberal and clinical social work discourses. It is important to understand what is constructed as a normative body, and how dominant discourses support the creation of this universal subject.

Neoliberal capitalism not only demonstrates its ideals in the sphere of the market, but in bodies as well (Guthman, 2009). The neutral body assumed by the neoliberal state is a White, able-bodied, middle-class, heterosexual, masculine body (Cooper, 1997; Gatens, 1996). This universal subject reflects fantasies about the value and capacities of that body that influence our social and political behaviour (Gatens, 1996). The universal subject is the ideal human being that conforms to, and operates within, dominant discourses in society (Davies, 2005). We accord privilege to bodies that represent this norm, and the norm is always reflected in our ways of speaking and in what we speak about (Gatens, 1996). Of language, Howe (1994) writes,

Those with power can control the language of the discourse and can therefore influence how the world is to be seen and what it will mean. Language promotes some possibilities and excludes others; it constrains what we see and what we do not see. (p. 522) 
"Many acts of oppression at the personal level reflect the notion of an inferior and/or ugly body type" (Mullaly, 2002, p. 52). Fat people suffer from being labelled insultingly (I have personally been called things like Ugly, Fatty, Pig, Cow, Whale) and name-calling devalues members of subordinate groups by negatively accentuating differences between the dominant and subordinate groups. It reflects the belief that characteristics of the dominant represent the norm or universal standard and that anything not meeting the standard is open to ridicule and insult (Mullaly, 2002). Characteristics assigned to members of subordinate groups include: irresponsibility, laziness, intellectual deficiencies, asexuality, and sexual degeneracy (Mullaly, 2002).

The neoliberal subject is defined by consumption, individual responsibility, and selfcontrol (Davies, 2005; Guthman, 2009). Fat people are often downwardly mobile, so they often fall short of the income necessary to have the capacity to purchase goods and be valued societally (Davies, 2005; Ernsberger, 2009). A crucial element of the neoliberal order is a shift from dependence on social support and the dream of possessions and wealth for each individual who "gets it right" (Davies, 2005). Fat people are individually blamed and pathologized for failing to "get it right" in the neoliberal system, rather than the focus being on removing the social and cultural barriers that prevent them from having the same opportunities as the dominant group (Herndon, 2002; Stubblefield, 2007).

Neoliberal governmentality requires subjects to participate in society both as enthusiastic consumers and as self-controlled individuals (Guthman, 2009). Those who can achieve thinness amid plenty are seen as representative of rationality and self-discipline that those who are fat must logically lack (Guthman, 2009). Neoliberal, capitalist, and fundamentalist Christian 
discourses of productivity and self-deprivation as markers of success and privilege are evident in this line of reasoning.

\section{The Medical Model}

The medical model is the dominant theoretical framework that deals with "obesity" in the twenty-first century (Cooper, 1997). An abundance of medical evidence and "common sense" knowledge supports the current way fat bodies are framed in Western societies. Being fat is widely accepted as undesirable because it is seen as innately unhealthy and is theoretically the primary cause of a multitude of preventable diseases (Cooper, 1997). Even in the face of the unparalleled failure of the medical model to find a "cure" for fatness, obesity experts continue to turn to this framework for intervention options (Solovay, 2000). Cultural narratives of fatness are fueled more by the drive towards normative bodies than by solid medical evidence (Herndon, 2002).

Fat people have been consistently maltreated by a medical establishment seeking to eliminate the obese (Solovay, 2000). Yet in a sense, fatness defies medical model analysis because the diagnosis is subjective and unstable (Herndon, 2002; Stubblefield, 2007). Part of the power of fat is that no standard definition exists (Herndon, 2002). Fat can mark any person, and can be used as a basis of stigmatization in a wide variety of situations, particularly in the medical context (Herndon, 2002). This label has been and continues to be applied to people with a wide range of characteristics (Stubblefield, 2007).

LeBesco (2009) states, “Escalating levels of hype about the 'obesity epidemic' are apparent in medicalized rhetoric about body size as first and foremost a health issue (conveniently obscuring the moral and aesthetic objections that fuel the demonization of fat 
bodies)" (p. 71). This demonstrates that it is important to be critical about who is conducting obesity research, why they are looking at these topics, and what interests they are serving. Much of the existing research about obesity issues comes from the American Obesity Association (AOA) (Harding \& Kirby, 2009). Their sponsors include: The American Society for Metabolic and Bariatric Surgery, International Federation for the Surgery of Obesity, Jenny Craig, Inc., Knoll Pharmaceutical Company, Weight Watchers International, Inc., Slimfast, and Medeva Pharmaceuticals, to name a few (Harding \& Kirby, 2009). Yet it is not recognized as a conflict of interest that the funding for the AOA (which frames obesity as a "health crisis", an "epidemic", and openly declares a "war" on these bodies) comes from commercial weight loss programs, pharmaceutical companies who sell weight-loss drugs, and doctors who profit from performing surgery on fat people (Harding \& Kirby, 2009).

\section{The Body Mass Index}

The Body Mass Index (BMI) has had a huge impact on the ways we categorize and view obesity. The BMI is a weight-for-height tool that is privileged by the medical model and upheld as the standard for classifying bodies ("Health Topics: Obesity", 2013). The World Health Organization defines a person with a BMI greater than or equal to 25 as "overweight", and a person with a BMI greater than or equal to 30 as "obese" ("Health Topics: Obesity", 2013). The Body Mass Index is:

...a macro tool for normalizing the population - for taking a vast and diverse group of people and establishing a 'normal range' to which every individual bears some relationship. Deviation from the norm is then (falsely) read as proof of behaviours that can be pathologized, just as conformity is (falsely) taken as evidence of health and good conduct. Power here thus operates both at an epidemiological level and at the level of the production of a weight-based moral identity in the individual. (Heyes, 2006, p. 133) 
Deeming specific BMIs as pathological is a political rather than scientific act (Ernsberger, 2009). The Body Mass Index not only fails to account for various physical factors, it doesn't acknowledge in any way that social factors are also very influential on bodies. Race, class, food access and nutrient intake, sleep quality, geographic location, access to quality medical care, weight cycling, and exposure to weight-based stigma are all things that can affect a person's BMI (Bacon \& Aphramor, 2011; Burgard, 2009; Ernsberger, 2009; Fee, 2006). For example, Type 2 diabetes, the disease most linked with obesity through BMI-supported discourses, is increasingly being associated with poverty and marginalization, rather than body weight (Bacon \& Aphramor, 2011). Understanding human bodies only in terms of weight and height is a complete oversimplification that makes intersectional experiences invisible.

Almost every study on obesity begins their introduction with a discussion about how obesity is astronomically on the rise. One of the reasons for the enormous jump in measurably larger bodies was the restructuring of the BMI scale in 1998. As a result of the BMI cut-off points that define "overweight" and "obese" being lowered, millions of people became fat instantaneously (Wann, 2009). In fact, BMI profiling overlooks 16.3 million "normal weight" individuals who are not healthy and identifies 55.4 million overweight and obese people who are not ill as being in need of treatment (Bacon \& Aphramor, 2011). Burgard (2009) goes even further to say that $91 \%$ of what accounts for health outcome has nothing to do with BMI. Yet the Body Mass Index is the premise upon which we classify bodies, and upon which vast amounts of medical obesity research are funded. This demonstrates that the empirical basis for fat issues is often discursively constructed (Friedman, 2012). 


\section{Health and Health Education}

Health is a problematic concept when linked with weight. Health is not a number, but rather a subjective experience with many influences. Stepping onto a scale cannot prove a person healthy or unhealthy (Wann, 2009). However, Western societies are currently experiencing a valorization of health that influences people and organizations (Mik-Meyer, 2010). Health policies today have been embedded with cultural values, and speaking in the name of health is one of the most powerful rhetorical devices. Health has come to be viewed as a duty, and the body can be understood as a locus of power where duty and subordination play out (Mik-Meyer, 2010). Obesity is considered a loss of sovereignty over the body and has typically been regarded as "both a measure of moral laxity in the individual and sign of social corruption" (Mik-Meyer, 2010, p. 388).

In this century, health has become increasingly important politically as a major point of contact between governments and the population (Gastaldo, 1997). Health education is considered a very important part of preventing disease and promoting health. Gastaldo (1997) has linked health education efforts with Foucault's notions of bio-power (the mechanisms employed to manage the population and discipline individuals). Health education contributes to the exercise of bio-power because it deals with the norms of healthy behaviours and promotes discipline for those who fail to achieve good health. Focusing on individual bodies or the social body, health professionals are entitled by scientific knowledge and power to prescribe "healthy" lifestyles. The clinical gaze is omnipresent and its objective is to promote health and a disciplinary society (Gastaldo, 1997). What health education does is construct identity. Health education builds up representations of what is expected from "healthy" and "sick" people, and reinforces these representations through complex systems of rewards and punishments (Gastaldo, 
1997). For example, as I will discuss in the primary research section, health professionals treat fat patients poorly, based on the ideas already held about their weight making them sick.

\section{Primary Research}

Having reviewed some literature that is consonant with my theoretical framework, I was interested to see what primary research studies on obesity would unearth regarding discursive assumptions about bodies. I analyzed many studies and separated my findings into notable themes. These studies were found through following bibliographies in the Fat Studies Reader (2009), as well as searching the Ryerson library for studies containing the words "obese/obesity", "fat", "stigma”, and "body image". The amount of social work scholarship on fatness is currently extremely limited. The literature that does exist focuses on obesity as a public health and public policy issue and uses words like "alarming", "epidemic", and "public health crisis" (Eliadis, 2006; Lawrence, Hazlett, \& Hightower, 2010; Melius, 2013; Sealy, 2010). Friedman (2012) is the singular example of social work literature that takes a critical and social justice orientation to fatness and fat issues, challenging dominant narratives of fat bodies. I want to expand the research done on fatness and move away from positivist research focused on what other people and "experts" have to say about fatness. It is important to fill this research gap by conducting research that brings forth the voices of fat people and their understandings of their experiences.

\section{Fatness and the Media}

Many studies have been conducted that claim that media consumption increases obesity (Hendrix, Carroll, \& Downs, 2014; Marshall et al., 2004; Stein, 2011; Vandewater, Shim, \& Kaplovitz, 2004). It is much harder to find research that discursively analyzes how media 
presents obesity. Boero (2006) does a discourse analysis of how the New York Times presents the obesity "epidemic". My MRP, with a Canadian focus that goes beyond a single paper, fills a research gap. Social work rarely analyzes popular culture, so by selecting the Canadian Press as my focus I am potentially broadening our understandings of what impacts and influences the social work profession. My research aims to highlight the importance of the media and popular culture as tools that uphold certain discourses that we all internalize.

\section{Fatness and Children}

Many obesity studies focus on children and adolescents (Cramer \& Steinwert, 1998; Davison \& Birch, 1998; Eaton et al., 2005; Latner \& Stunkard, 2003). As early as 3 years old, children attribute negative traits to fat figures (Cramer \& Steinwert, 1998). By 4, children consciously use body size as a category for stigmatization (Cramer \& Steinwert, 1998). At 5 years old, children clearly focus on fatness as the basis for stigmatization (Cramer \& Steinwert, 1998). Since children make negative judgments based on weight from a very young age, Davison \& Birch (2001) studied self-concept in 5 year old girls who were overweight or obese. They found that girls who weighed more had lower body esteem and lower perceived cognitive and physical ability. Concerned parents often restricted their children's food access, and directly or indirectly criticized them about their weight (Davison \& Birch, 2001). Latner and Stunkard (2003) found that by 10-11 years old, stigmatization of obesity had increased, and that obese children were rated as less desirable than children with a variety of disabilities. Overweight high school students are more likely to have suicide ideation and attempt suicide (Eaton et al., 2005).

Obesity in children and adolescents is currently being publicized as a global health issue, and the social and health consequences and shame that results from singling out those bodies as abnormal and pathological is ignored. Public health campaigns that focus on childhood weight 
issues, often do not provide constructive and blame-free ways to address weight, and can be detrimental to children's mental health (Davison \& Birch, 2001).

\section{Fatness and Employment}

Several studies looked at fatness and employment issues (Baum \& Ford, 2004; Larkin \& Pines, 1979; Rothblum, Brand, Miller \& Oetjen, 1990). Larkin \& Pines (1979) found that employers see overweight persons as significantly less desirable employees. Overweight people were seen as less competent, less productive, not industrious, disorganized, indecisive, inactive, and less successful (Larkin \& Pines, 1979). In a simulated work setting, these stereotypes resulted in equally qualified overweight applicants being significantly less likely to be recommended for hiring (Larkin \& Pines, 1979). Even if an overweight person is hired, they are more likely to experience types of employment discrimination such as being denied promotions or raises, demoted, fired or pressured to resign, being questioned about their weight or urged to lose weight (Rothblum, Brand, Miller \& Oetjen, 1990). Obese employees also persistently earn less than their non-obese peers (Baum \& Ford, 2004).

These studies illustrate why fat people often have a lower socioeconomic status than thin people (Ernsberger, 2009). Weight discrimination and stigma can result in unemployment or low-paying work (Ernsberger, 2009). Fat and thin people score equally on intelligence tests, but intelligent fat people are far more likely to end up living in poverty than intelligent thin people, because of the multiple employment barriers (Ernsberger, 2009).

\section{Fatness and Health Care}

Many studies on fatness focus on health care issues (Agell \& Rothblum, 1991; Drury \& Louis, 2002; Hebl \& Xu, 2001; Myers \& Rosen, 1999; Schwartz, Chambliss, Brownell, Blair \& 
Billington, 2003). Psychologists who practice therapy are negatively influenced by a client's weight (Agell \& Rothblum, 1991). Physicians view heavier patients significantly more negatively and spend less time with them (Hebl \& Xu, 2001). Physicians are also more likely to recommend psychological counselling to heavier individuals, suggesting a belief that overweight patients are unhappy and unstable (Hebl \& Xu, 2001). Even health professionals that specialize in obesity display significant implicit and explicit anti-fat biases, believing that fat people are lazy, stupid, and worthless (Schwartz et al., 2003).

People with higher BMIs have many experiences with being misdiagnosed or not diagnosed at all because medical professionals assume that the only explanation for their symptoms is their weight (Harding \& Kirby, 2009). Physicians indicated that they would prescribe more weight-related tests for obese patients, regardless of what their symptoms were (Hebl \& Xu, 2001). Overweight and obese people have also been denied transplants, joint replacements, and elective surgery, because such interventions are seen to be "wasted" on people with higher BMIs (Harding \& Kirby, 2009). Fat people have died from this medical neglect, a fact that is not considered when linking obesity with higher rates of disease and death (Harding \& Kirby, 2009).

Given the amount of fat stigmatization and discrimination displayed by medical professionals, it is not surprising that as body weight increases the rate of health care delay and avoidance also increases (Drury \& Louis, 2002). Overweight and obese women cited several reasons for delaying or avoiding health care, including having gained weight since the last visit, having to get weighed when they go in, being told to lose weight, and undressing in the providers office (Drury \& Louis, 2002). Frequently experiencing stigmatizing situations is associated with more mental health symptoms, more negative body image, and more negative self-esteem 
(Myers \& Rosen, 1999). However, despite these studies, poor health in fat people is more commonly discursively constructed as an individual problem and an individual failure. Fat people are blamed and stereotyped for their poor health, and the broader barriers to health care and consequences of fat stigma are rarely addressed.

We rarely see the analysis that fat people might experience poorer health because stigma keeps them from seeking healthcare when health problems are in the early stages and more easily addressed. Going to the doctor can be emotionally and physically treacherous when "there's a one in four chance that the nurse who weighs you will find you repulsive and the physician who treats you is likely to think you're lazy and out of control (even if she doesn't think she's biased)" (Harding \& Kirby, 2009, p. 51). It is very important for fat people to seek out fatfriendly physicians. You can look for a good physician by starting before you need one, doing some research, calling and inquiring about the doctor's policies on dieting, and insisting on high standards of treatment (Harding \& Kirby, 2009).

\section{Fatness and Gender}

All of the studies were thematically linked by the gendered experiences of fatness. No matter what area the study was focusing on, women and girls were more affected by fat discrimination than men and boys. Some studies only focused on women or girls (Davison \& Birch, 2001, Drury \& Louis, 2002; Robinson, Bacon \& O’Reilly, 1993). Obese women have more of a wage penalty than obese men (Baum \& Ford, 2004). Women's wages start to decline if their Body Mass Index is over 25, whereas men's wages don't start to decline until their BMI is over 30 (Baum \& Ford, 2004). Therefore, men can be significantly fatter than women before they experience the same consequences. 
Obesity is considered unattractive, especially in women (Rothblum, Brand, Miller \& Oetjen, 1990). Women report lower self-confidence because of their weight, and more attempts to conceal their weight than men (Rothblum, Brand, Miller \& Oetjen, 1990). Myers \& Rosen (1999) studied clinical subjects who were seeking help for weight management, and their sample was overwhelmingly female. Clearly women are more likely to seek help for weight management because all the other studies demonstrate that women are more likely to be stigmatized for their weight.

An interesting gendered theme also emerged showing that women and girls also rate fatness more negatively than men and boys (Agell \& Rothblum, 1991). Girls associate fat figures with "meanness" more often than boys (Cramer \& Steinwert, 1998). Girls have a stronger preference for thin playmates than boys (Cramer \& Steinwert, 1998). Female obesity specialists expressed significantly stronger anti-fat bias, believing that fat patients were lazier and stupider than male obesity specialists (Schwartz et al., 2003). This trend could be connected to Foucault's (1979) theorizing that the success of a society's imposition of discipline upon bodies depends on those bodies learning to regulate themselves. As the studies have demonstrated, there is an immense amount of pressure for women in particular to remain thin, and they experience the most stigmatization when they transgress this boundary. Therefore, women learn to regulate themselves and police other women's bodies more stringently.

\section{Race and Class Issues}

The studies examined either had a sample where the majority of participants were white, or a study where all the participants were white (Cramer \& Steinwert,1998; Davison \& Birch, 2001; Drury \& Louis, 2002; Eaton et al., 2005; Latner \& Stunkard, 2003; Robinson, Bacon, \& O'Reilly, 1993). The majority of participants were also middle to upper class (Agell \& 
Rothblum, 1991; Davison \& Birch, 2001; Hebl \& Xu, 2001; Larkin \& Pines, 1979; Robinson, Bacon, \& O’Reilly, 1993; Schwarz et al., 2003).

The lack of ethnic and socio-economic diversity of the sample does not accurately reflect the multiplicity of fatness. Fat realities are very influenced by other aspects of social location. Fatness is more common among minority groups, including Aboriginal peoples, Black people, and Hispanic people, and often further magnifies discrimination (Ernsberger, 2009). The participants in the Davison \& Birch (2001) study were all white and middle class, and in order to qualify the girls had to be living with both biological parents. This study would have been more valid if it had collected data from different kinds of families. For example, single mothers are more likely to have a lower socio-economic status, which would affect their family's access to nutritional food. (Ernsberger, 2009). Lack of access to nutritional food and living in lower socioeconomic areas have been significantly linked with fatness (Ernsberger, 2009).

The Larkin \& Pines (1979) study was the only one that named the whiteness of their sample as a limitation. They stated that it was possible that persons of other ethnic or class backgrounds would have different perceptions of the overweight condition, or even what constitutes "overweight" (Larkin \& Pines, 1979). Eaton et al. found evidence of this when looking at White, Black, and Hispanic high school students (2005). Among White students, BMI was significantly associated with suicide attempts, but BMI was not significantly associated with suicide attempts among Black students (Eaton et al., 2005). Some literature suggests that racialized communities sometimes have different standards of attractiveness, and the label fat gets applied differently. For example, in one study a participant stated that, "I sort of feel that as a Black woman it's more "okay" to have an hourglass-shaped body as opposed to a stick thin body" (Blank, 2011, p. 36). Focusing on more diverse participants would have presented data 
that was richer and more robust. The majority of these studies used positivist research techniques that homogenized and generalized experiences of fatness.

"People end up with different baggage about fatness because of their ethnicity, their skin colour, their sexual orientation, and their socio-economic class” (Blank, 2011, p. 4). More complex understandings of fatness are not possible when the interaction of fatness with other identities is ignored and the white, middle-classed female experience of fatness (which itself is much more diverse than the studies acknowledged) is the only experience represented. Fat bodies and fat identities must be understood in the context of different experiences of gender, race, and class (LeBesco, 2004).

\section{Queerness and Fatness}

Though these primary studies focused on participants that were presumed to be heterosexual, there are important intersections between fatness and queerness that should be researched and highlighted. I have always been interested in the different ways fat bodies are perceived in queer spaces, as opposed to dominant, heteronormative spaces. I could not find literature discussing or comparing these experiences, but I can speak to my own experience. I genuinely feel that my body is more accepted within queer spaces and I generally feel more desirable to queer folk than I do to heterosexual males. Some queer people already think critically about dominant discourses of masculinity, femininity, heterosexual relationships, and desire, and I feel within queer communities there is more of an uptake of critical perspectives on fatness than in mainstream culture.

"Fat activism is a particularly "queer-flavoured" movement" (Hill, 2009, p. 1). Queer people bring the language and identity politics of their communities into fat activism, in order to 
claim fatness as an empowering and subversive political identity (Hill, 2009). However, in the queer community, as anywhere, fatness can be controversial and despised (Blank, 2011). But the influence of feminist politics on the queer women's community means that women are less likely to be judged overtly for their appearance than they are in mainstream heterosexual culture (Blank, 2011).

Gay male culture also encompasses "bear" and "chub" cultures (Blank, 2011). Although many gay men are immersed in mainstream gay male culture that puts a large emphasis on thin and beautiful bodies, queer men's tastes and desires fall across a vast spectrum just like any other group's (Blank, 2011).

Fatness can be an asset to some trans people and can pose a hurdle for others (Blank, 2011). Medical professionals make fatness an issue for trans people. Doctors have been known to threaten to withhold hormones until weight loss occurs, because a commitment to a thin-centric feminine presentation shows that you are "really committed" to becoming a "real woman" (Blank, 2011, p. 56). Doctors may also contend that estrogen poses too many health risks for fat folk. Transmen often find they can get away with more fat than transwomen, and fat can help produce a more believably masculine body shape, which again speaks to how fatness is taken up in a gendered way (Blank, 2011).

\section{Fatness and Disability}

Aside from the Latner and Stunkard (2003) study showing participants pictures of children with disabilities, the primary studies did not touch on disability and fatness. Fatness and disability both disrupt social and economic hierarchies, crossing class and race lines to interrupt privilege 
(LeBesco, 2009). Discussions of similarities between fatness and disability are fraught with misunderstandings, stereotypes, and arguments on both sides.

As said earlier, fat is powerful because no standard definition exists (Herndon, 2002). Likewise, the question of who is disabled is confounding and contextual (Sherry, 2004). Both labels have been, and continue to be, applied to people with a wide range of characteristics (Stubblefield, 2007). Both fatness and disability draw attention to the fact that the norm itself is an unstable category (Stubblefield, 2007).

Fat people and people with disabilities both experience being stereotyped and discriminated against, and suffer emotional trauma within the health system (Cooper 1997; Sherry, 2004; Solovay, 2000; Stubblefield, 2007). Both groups experience lifelong attempts to "cure" their bodies and bring them closer to the norm, whether that is actually best for their bodies or not (Cooper, 1997; Stubblefield, 2007).

The eugenics movement is something that influences the experiences of both fat people and people with disabilities. Eugenics reflects a history with a dynamic set of discourses and practices that reflect what the socially powerful believe about the nature and meaning of intellect and civilization. Within the eugenics movement, people in positions of social power constructed and reconstructed certain groups as deviant to serve their own interests, and we are still seeing examples of this in contemporary neoliberal times (Stubblefield, 2007). Eugenic viewpoints were convenient for policy makers who found it easier to pathologize certain groups rather than take responsibility for shifting their social conditions (Stubblefield, 2007). There are many ways that eugenic ideals impact fat people and people with disabilities today. The new eugenics movement is aimed at abolishing aberrations deemed socially or aesthetically undesirable, whether they are life threatening or not (LeBesco, 2009). 
The possibility of finding genetic causes for fatness and disabilities that can be tested for prenatally heavily influence discourses about public policy, legal protection, civil rights, abortion, and social movements (LeBesco, 2009). When we place bodies under the microscope of science in the name of liberal projects of self-improvement are we searching for freedom from discrimination, or reinscribing deviance (Foucault, 1980; LeBesco, 2009)? Using biological research to discover and potentially "cure" diverse human conditions can just as easily lead to the proof of pathology and the justification for eradication (LeBesco, 2009).

Disability activists have fought long and hard for their rights. The creation of a social model of disability turns the focus back onto cultural attitudes and disabling environments rather than individual bodily deviance (Solovay, 2000). This has been an incredibly powerful tool of resistance within the disability community. Some fat people also believe that viewing their bodies as diseased or curable, rather than as affected by societal bias - that constructs them as unable, different, undeserving, and inferior - keeps progress from being made in terms of fat peoples' rights (Solovay, 2000). In this way, a social model understanding of disability is also very relevant to fat people. The disability community also includes many extremely diverse subgroups with widely varying experiences, physical and mental capacities, levels of oppression and needs (Solovay, 2000). I believe the fat community is equally diverse, and could learn a lot about the disability community's past collaborations in the struggle for equal rights. Both groups internally struggle from questions of who is fat enough or disabled enough to be included. Both groups also have certain subgroups that experience more marginalization that others, and have a more difficult time challenging dominant discourses. Extremely fat people and people with more challenging impairments are often denied their basic rights in ways that group members who 
conform more to dominant ideals of normalized bodies are not. This creates internal tensions that are difficult to mediate.

Many people from either the disability or the fat community believe that viewing weight as similar to disability belittles the experiences and difficulties of people with disabilities (Solovay, 2000). Appropriating the disability community's solutions is colonizing and disempowering (Cooper, 1997; Solovay, 2000). I myself have struggled with the tendency of developing social movements to piggy-back and co-opt the achievements and breakthroughs of other social movements. However, I believe that fat people suffer legitimate oppression and can gain a lot of knowledge, tools, and understanding from the disability community. Is it even

possible to share knowledge and find solidarity instead of co-opting and invisibilizing important differences when comparisons are such a contentious issue in the first place?

Unfortunately, whether or not you believe that fatness can be considered a disability, the fact remains that there are no federal laws that protect fat people from the effects of fat prejudice (Solovay, 2000). The only times that cases about fat discrimination have won in the courts have been when the fat plaintiff used disability laws to challenge discrimination (Solovay, 2000). Is it a reasonable stance that fat people should not be allowed to use the only laws that have been able to protect them because disability laws are not "for" them? Due to the current "war on obesity" in Western societies, I feel it is unlikely that the creation of anti-fat discrimination laws is something that will be widely supported.

\section{Epistemological and Research Paradigms}

Almost all of the studies were published in medical, psychological, or health-related journals (Agell \& Rothblum, 1991; Baum \& Ford, 2004; Cramer \& Steinwert, 1994; Davison \& Birch, 
2001; Drury \& Louis, 2002; Eaton et al., 2003; Hebl \& Xu, 2001; Latner \& Stunkard, 2003; Myers \& Rosen, 1999; Robinson, Bacon, \& O’Reilly, 1993; Schwartz et al., 2003). Even though most of these studies looked at stigmatization and discriminatory attitudes, they were located firmly within a positivist paradigm. The researchers did not locate themselves in any of the studies, they were merely reporters on the phenomenon of weight discrimination or fatphobia. Though the studies measured stigma, they still began from the premise that fatness is a medical condition, a disease, or a pathology. Many of the studies sought to measure discriminatory attitudes towards overweight and obese individuals, rather than doing qualitative research with fat people about their own experiences of discrimination (Agell \& Rothblum, 1991; Cramer \& Steinwert, 1998; Hebl \& Xu, 2001; Larkin \& Pines, 1979; Latner \& Stunkard, 2003; Robinson, Bacon, \& O’Reilly, 1993; Schwartz et al., 2003).

The methodologies were assumed to be neutral, there was no discussion about what assumptions were already made by using such methods. For example, Latner \& Stunkard presented participants with 6 drawings, 1 "healthy" child, 4 children with various different disabilities, and 1 obese child (2003). Participants were asked to rank the drawings in order of preference (Latner \& Stunkard, 2003). The researchers stated that the drawings were matched for height, facial appearance, and clothing, and that the drawings depicted White children (Latner \& Stunkard, 2003). However, there was no example of how the obese child was drawn, children with invisible disabilities were not acknowledged, and there was no intersectional analysis about how the results may have changed had the drawings not been of White children. I also felt that the structure of the study did nothing to combat ableism or fatphobia. Yet the drawings were just assumed to be a neutral tool used in the measurement of attitudes towards obese children. 
None of the studies were action or social justice-oriented. Most of the studies measured discriminatory attitudes and concluded with discussing the findings. Only two studies actually made recommendations to combat fat stigma (Cramer \& Steinwert, 1998; Drury \& Louis, 2002). Cramer \& Steinwert (1998) suggested that there needs to be a diversity of body types represented positively in the media, children's books, and movies (1998). They point out that fat bodies are typically associated with "ugly" characters or villains, and that this needs to change. I agree that this is a good starting point to reduce isolation. Seeing positive representations of my body as I was growing up would have been very helpful. Though some studies "measured" and demonstrated how fat people are discriminated against, the research was not undertaken to challenge and shift this marginalization. The research did not attempt to dismantle privilege or change the status quo, it merely reported on what negative conditions already existed.

\section{My Research}

My MRP research is interested in furthering critical conversations about fatness within social work education and practice. The primary studies showed discriminatory and fatphobic attitudes held by professionals in various medical and caring professions. I assume that social workers are also not immune to fatphobic biases, and that body discourses are constantly fighting for position in our practices and our lives, influencing how we practice and how our own bodies are read by those around us. I want to expand the research done on fatness, and move away from positivist research. It is important to fill this notable research gap by conducting research that has an antioppressive and social justice focus and pushes for a paradigm shift in the way we think about fatness. 


\section{CHAPTER 4. RESERCH DESIGN/METHODOLOGY Research Questions}

1. How do Canadian Press articles describe obesity?

2. What discursive tools do the articles use to convey ideas about obesity?

3. What power relations are demonstrated?

I carried out a modified critical discourse analysis of Canadian Press articles. The Canadian Press was created in 1917 to facilitate the exchange of news across Canada ("The Canadian Press", n.d.). Their website describes The Canadian Press as,

a dynamic, agile, bilingual news agency, driven by leading-edge technology and the ability to serve multimedia news to multiple platforms. It provides real-time text, photos, audio, graphics, video and online services to newspapers, broadcasters, publishers, websites, wireless carriers, cable companies, government and corporate clients. (n.d., para. 1).

The Canadian Press feeds most of the large daily newspapers in Canada, providing them with relevant news stories and articles ("The Canadian Press", n.d.). Looking at The Canadian Press transcends looking at the obesity articles in a single newspaper. Searching The Canadian Press Archives provides access to content that has been used for hundreds of media outlets across Canada.

I chose to look at The Canadian Press because the mass media, the publishing industry, and other cultural agents serve as conduits of cultural constitution and reconstitution, by "continually reproducing the language and symbolic universe of a society" (Adam, 1978, p. 30).

The media transmits dominant cultural messages, images, or products that define reality in ways that both privilege and marginalize (Mullaly, 2002). Mass media forms distribute depictions of dominant groups and social systems as the norm (Adam, 1978). 
Discourse analysis can be described as the study of "an interrelated set of texts, and the practices of their production, dissemination, and reception that brings an object into being" (Philips \& Hardy, 2002, p. 6). I am interested in the ways that obesity is brought into being and constructed through The Canadian Press articles. My method was informed by Foucauldian concepts of discourse and power and Fairclough's (2002) method of critical discourse analysis. Critical discourse analysis presumes that both the texts studied and the person studying them have political intent (Titscher et al., 2005). Part of my political stance is that I do not believe the Canadian Press articles will be neutral, discussions of obesity have underlying political agendas. Critical discourse analysis is concerned with social problems, and the researcher believes that society and culture are shaped by discourse but also create discourse (Titscher et al., 2005). Language reproduces and transforms discourse, and power relations are demonstrated through language. Critical discourse analysis sees discourses as historical and context-specific, embedded in particular cultures, ideologies, and histories (Titscher et al, 2005). This is relevant to obesity because, as discussed in my theoretical framework, fatness has meant different things and has been viewed differently throughout history (Parsons, 2012).

A critical discourse analysis methodology questions what a discourse is, and looks at samples from a broad variety of sources to begin to answer that question. I am calling my design a modified critical discourse analysis because I am only analyzing samples from a single source, The Canadian Press. I chose to look only at a single source instead of pulling from advertisements, television shows, movies, textbooks, magazines, blogs, etc. because of the constraints of the research timeline.

My discursive assumptions are drawn from my theoretical framework and my literature review, as well as from a wealth of personal experience living in a fat body. To briefly 
summarize from previous chapters, I believe that dominant obesity discourses are concerned with health, disease, morality, and forcing fat bodies to become thin. I am interested in whether these discourses will be reflected in 20 Canadian Press articles written within the past year. I chose to do 20 articles because that seemed like a reasonable amount for in-depth analysis. I felt it would be more fruitful to deeply analyze a smaller sample of data than to do a shallow analysis of a larger number of articles. Though my small sample limits my ability to draw broader conclusions about fatness and discourse, I was able to do an extensive analysis that yielded some of the more covert and insidious ways that fat bodies are demonized.

I chose this methodology because I believe that a lot of the "common sense" knowledge that leads to the stigmatization of fat bodies is the result of discourses that are operating and creating certain power relations. This research method focuses on the ways dominance and inequality are enacted, reproduced, and resisted in social and political contexts (Schiffrin, Tannen, \& Hamilton, 2001). As previously stated, the pervasiveness of obesity discourses is not yet thought about widely or critically within social work. I wanted to focus on a specific area that could yield good examples of how varied obesity discourses can be, and relate my thematic findings to anti-oppressive practice. I believe a critical understanding of fatness can be built through an understanding of dominant body discourses. This critical understanding can then be linked with practice through social work education. This MRP felt like a perfect space to begin to push back and challenge discourses about fatness that are assumed or taken for granted, as well as a way to combat silences around fatness in social work that I believe are indicative of wider social discourses that influence the way we think.

Once again, my theoretical framework led me to define discourse as follows: 
Discourses about bodies are shifting ways of conveying, reinforcing, and reproducing ideas relating to the ideal neoliberal subject. These discourses utilize understandings of economy, pedagogy, medicine, morality, and law to define bodies in specific ways. Elements of certain discourses include ethos, food, exercise, clichés, sayings, slogans, vocabulary, photos, fears, conflicts, contradictions, blame, silences, what isn't said, what is assumed, rules, policies, programming, education, health, public, private, statistics, referencing, and transformation.

I conducted a search of the Canadian Press archive, searching for articles written between April 2013 and May 2014 that had the word "obesity" or "obese" in the title or anywhere in the text. The articles in the Canadian Press archive do not include pictures, so after selecting my 20 articles I conducted Google searches of each article title in quotations and saved the photos associated with the articles in a file. My definition of discourse helped guide my selection of the 20 articles. I made sure from an initial scan of the article that it contained at least two elements of my discourse definition, for example selecting an article that focused on educating about obesity, using nutrition as a tool, or an article that defined obese bodies as unhealthy and immobile, and had pictures showing hospital imagery. I purposefully chose a wide sample of different kinds of articles, representing news articles, editorials, and feature articles.

I drew heavily on Poole's (2007) method of data analysis, first examining each article for key words and phrases that stood out. These words were circled and written in the right hand margin of each transcript (Poole, 2007). When I had searched for key words in all the articles, I collected and combined all the margin words in a separate file (Poole, 2007). I then sorted the words into five main categories. With these categories in mind, I then returned for a second reading of the articles, searching for a wide array of examples from each of the categories 
(quotes, phrases, statistics). Through several more readings of the data, three main discourses began to emerge.

Throughout my readings, I constantly brought my awareness back to my reactions, and made lots of notes as I was reading. I am not immune to discourses, and I have a particular set of counter-discourses about fat bodies that inform my theoretical framework. Part of being critical about my place in this research was to not jump to the hard conclusion that mass media would universally demonize obese bodies. I constantly reminded myself to stay mindful, open, and welcoming to refutations and surprises in the data (Poole, 2007). I wanted to focus on how close the articles were to my definition of discourse, but I also wanted to make note of the ways in which they veered off. Discourses have rules, and in the Discussion section I will be transparent not only about where I discovered rules in dominant discourses, but where the articles triggered a reaction in me because they were transgressing my discursive rules. This MRP contains not only an analysis of text, but it produces its own discourse which is informed by my theoretical framework (Cheek, 2004).

I had several ethical considerations when conceptualizing this research. I was concerned about potential risks for myself and others. Reading articles about obesity that could be judgemental or problematic in many ways could bring up issues for me as a fat person. It is difficult as a person who has struggled with being bullied or judged for their weight to come face-to-face with societally accepted negativity towards fat bodies. I chose to use those moments of discomfort or upset as discursive learning opportunities. I critically reflected on why I was feeling uncomfortable, what was causing my reaction and why it was important for my research. I elaborate more on those moments in the Discussion section, because it is important for me not to present myself as an objective researcher that was somehow removed from the data. 
Everything about my reactions guided my analysis, and I am committed to being transparent about that.

I also considered the risks to potential future readers of my MRP. It might be difficult for fat people to read it, just as some of the articles were difficult for me to read. It also might be difficult for non-fat people to read it and be faced with ideas about their body privilege that they might not have considered. I am aware that discussions about fat make many people uncomfortable for a variety of reasons. Dominant discourses about fatness affect everyone, with any kind of body (Friedman, 2012; Wann, 2009). I hope that the readers who do seek out my MRP understand the potential discomfort they may experience, and do what is best for them, including not continuing to read.

\section{Limitations}

My research design had some limitations. The main limitation is that my sample was only Canadian Press articles. This narrow focus means that I cannot draw broader conclusions about obesity discourses and how they are operating in our society. I can draw conclusions about how the mainstream newspaper media is presenting and upholding these discourses, but this is only one kind of media, and the media itself is only one contributor to discourse.

Another limitation was that I did not look at a larger number of articles from a broader time frame. This research is a very small snapshot of a much larger picture. I would have preferred to select articles from the past 5 years to see if I could identify any shifting discourses or the ways that new fat discourses were jockeying for position and old ones were losing some ground. However, with the number of articles written on obesity annually, and the number of articles I felt I could reasonably analyze within the time frame it was not possible to go broader. 
I also feel that a limitation of my MRP was my own inexperience as a researcher. I almost regret choosing discourse analysis as my methodology. It would have been easier to select a methodology where the steps to conducting research were much more clearly laid out. I was and am uncomfortable with having the research be so completely guided by my own interpretations and impressions, because I felt a lot of uncertainty about the process. It was extremely difficult to unpack notions of the researcher as an expert, even within our antioppressive Master's program. I struggled with feelings of inadequacy as a researcher throughout the entire process. I tried to at least be transparent about my moments of uncertainty and to do ongoing work focusing on becoming comfortable with the idea that I was not any sort of expert, and that I may never conduct research that I do not feel uncertain about. 


\section{CHAPTER 5. FINDINGS}

In this chapter, I will outline the findings from the 20 Canadian Press articles I analyzed. The data yielded discourses that support certain constructions of obesity which are influenced by complex power relations. The three main discourses evident in the articles were: Mother Blame, The Medical Model, and Economics. These discourses while distinct, also overlap and intersect and I will be highlighting some of the commonalities and differences between them.

\section{Mother Blame}

Many articles focused on families and mothers as the key to lowering obesity rates. 7 articles focused on childhood obesity and the family. "Childhood obesity" was mentioned 17 times across the articles, "family/families" was mentioned 19 times, and "mother" was mentioned 12 times. Though families in general are often targets of blame in the obesity epidemic, the articles demonstrated gendered power relations by specifically targeting mothers. There is a distinct trend of mother blame in both common sense and professional understandings of the causes of and the interventions needed to counter childhood obesity (Boero, 2009). "The weight of one's children has increasingly become a litmus test of good mothering" (Boero, 2009, p. 113). As with other examples of mother blame, evaluating the fitness of mothers based on the size of their children obscures larger structural issues of racism, economic inequality, fatphobia, and sexism.

The articles brought up mothers in a variety of ways. One article specifically focused on how obese mothers tend to have children who become obese, and promoted weight-loss surgery as a solution for "breaking this unhealthy cycle" (Neergaard, 2013). Canadian researchers studied children born to obese women, plus their brothers and sisters conceived after the mother had undergone weight-loss surgery. Children born after their mother had the surgery and lost weight were slimmer than their siblings. "What's clear is that obesity is not just impacting your 
life, it's impacting your child," said Dr. Murphy of Duke University (Neergaard, 2013). This statement discursively constructs mothers as responsible for the obesity epidemic. This power relation does not acknowledge that this study had a sample size that was extremely small, nor that it still remains to be seen whether weight-loss surgery had a lasting effect on the children's weight.

Breast-feeding was mentioned 10 times across the articles. A few mentioned that breastfeeding children for longer helps them maintain a healthy weight (Italie, 2014; Stobbe, 2013). This focus on breast-feeding creates another way for the actions of mothers to be policed. Mothers may choose not to or be unable to breast feed for a variety of reasons, but now breastfeeding has become a tool in the "war on obesity", touted as something mothers must to do to keep their child from becoming fat.

Lower obesity rates were linked to mothers who controlled what their children ate. (Italie, 2013; Italie, 2014; Marchione, 2014; Stobbe, 2013). One article discussed the representation of unhealthy food choices in children's books (Italie, 2013). This article demonstrated a clear power relation that discursively constructed "good" mothers and "bad" mothers. It featured mother and children's book writer Leslie Patricelli defending her choice to feature cake and other "empty calorie foods" in her books. Patricelli is quoted as saying, "All you have to do is watch a kid eat a piece of cake to know that they're in heaven" (Italie, 2013). The article went on to promote other obesity-fighting authors and anti-obesity activists including mother and picture book illustrator Betsy Johnson, who depicts "healthy foods" in her books. She distances herself from books that show "junk food" and says, "That's not how I've ever fed my kids" (Italie, 2013).

This article demonstrates Foucault's (1980) discussion of how an action is not only moral in itself; it establishes a moral conduct that commits an individual to other actions always in 
conformity with values and rules. Johnson estabished herself as in line with universalizable moral codes based on food choices, and she is therefore framed as an ethical subject, a "good mother". This article reduces the causes of obesity to mothers and the food choices they make for their children, rather than acknowledging broader systemic barriers that might keep mothers from always providing their children with home-cooked, healthy food.

Only one article focused on some of the systemic barriers to food (Matheson, 2014). Many mothers in poor urban neighbourhoods have limited access to supermarkets, and corner stores are a critical source of food (Matheson, 2014). Many purchases made in corner stores are calorie-rich and nutrient-poor, for example chips, candy, and soda, because this is what corner stores stock. This contributes to higher rates of obesity in low-income neighbourhoods. When the articles promote discourses of maternal responsibility for family nutrition, what those discourses cover up are the pervasiveness of class divides and poverty.

In contrast to "bad" mothers, who need to begin actively preventing obesity in their children, the articles discursively constructed Michelle Obama as the perfect mother and obesity fighter. Michelle Obama's anti-obesity campaign is mentioned as part of the solution to raise awareness and solve the "problem of our generation" (Italie, 2014). Michelle Obama also promotes the discourses of "good" and "bad" foods, and she is focused on helping people cook more meals at home (Superville, 2014). She believes that home-cooked meals are healthier and cheaper than restaurant meals, and can be prepared in less than 30 minutes. During the promotion of her home cooking initiative, Michelle Obama frequently mentions her own mother, a woman who "kept a strict food budget, planned her meals for the week and went grocery shopping every Saturday" (Superville, 2014). This is fully in line with the discursive construction of a "good mother" that the articles presented. 
The discourse of Michelle Obama being the perfect mother and obesity fighter is supported through the images of her that are presented with the articles. Michelle Obama is always shown smiling, usually with "healthy" foods or surrounded by a group of children being physically active.
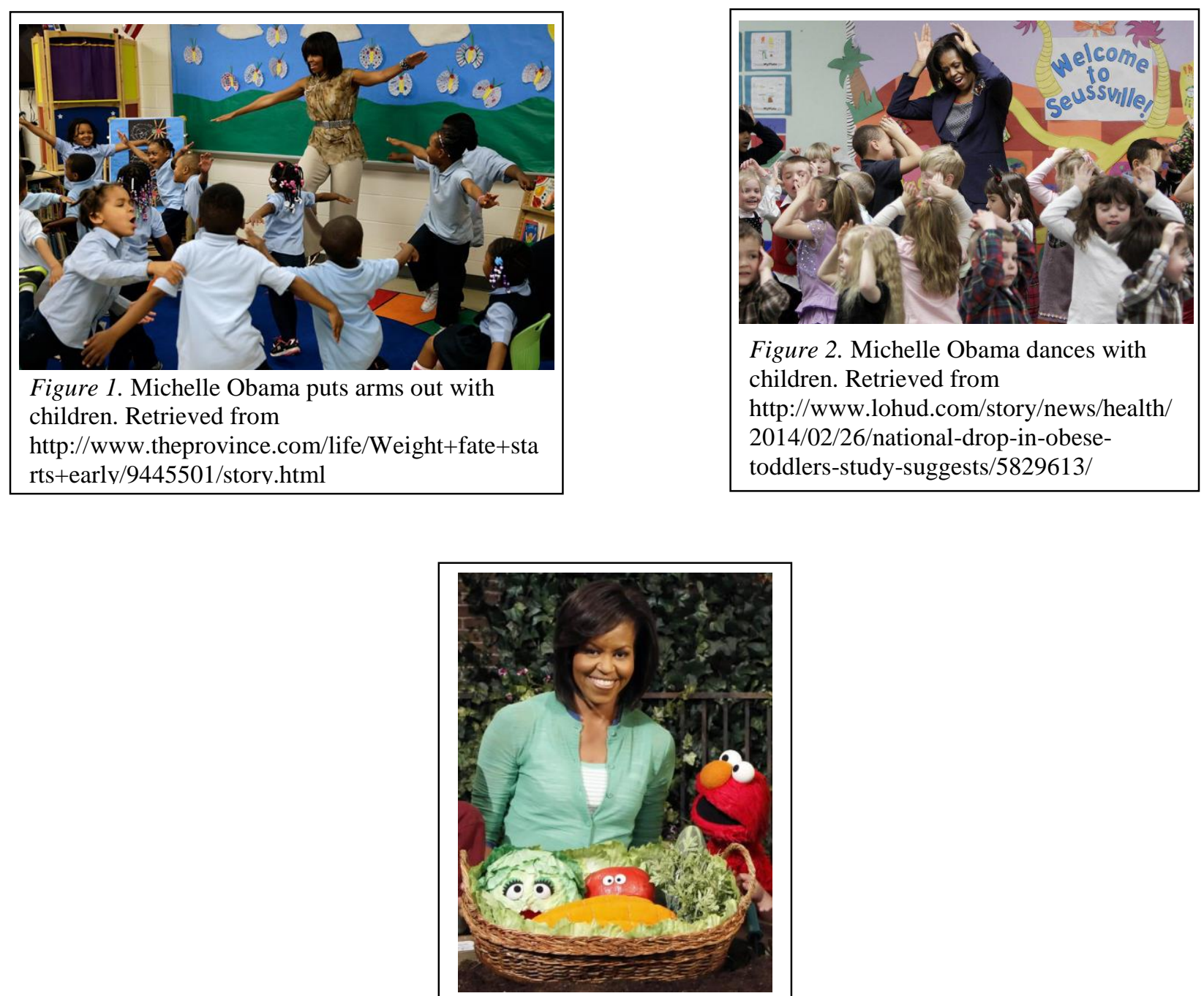

Figure 3. Michelle Obama on Sesame Street. Retrieved from http://www.usatoday.com/stor y/news/nation/2014/02/25/chil d-obesity-drops/5813395/

The photos of Michelle Obama engaging in "fun" physical activity or teaching children about healthy foods present her as the ultimate maternal figure, taking the time to educate and support these children in a way that their own mothers won't. Her presence as a mother and as 
someone who is engaging with the obesity issues in a way that is supported by dominant discourses automatically constructs in opposition mothers that don't feed their children the “right" foods, don't engage in physical activity with them, or don't adequately battle the childhood obesity epidemic. We need to ask critical questions about who these "other mothers" are, and why they may not be engaging with the obesity discourse in the "correct" way. These mothers are only given a voice to implicate and shame them, not so that they can voice the complexities of their experiences.

\section{The Medical Model}

The medical model is the most overtly operating discourse in the articles. All of the articles defined health in a solely weight-based, medical way. This viewpoint did not consider all physical, emotional, social, occupational, intellectual, spiritual, and ecological aspects of health (Bacon \& Aphramor, 2011).

A quarter of the articles focused on weight-loss surgery and weight-loss drugs. Various kinds of weight-loss surgery were mentioned 52 times across all articles, and weight-loss drugs were mentioned 9 times. Doctors were a strong presence in most of the articles. The word "doctor" was mentioned 34 times throughout the articles. 22 doctors were quoted in the articles, with some articles quoting multiple doctors. These "experts" were given a voice and were supported by the discourse.

The words that the doctors used to frame obesity demonstrated a particular discursive stance. The words "Fighting", "epidemic", "tackle" and "war" appeared many times. Quotes that stood out for me include: 
"We are telling people and doctors that it is not OK to be obese, even though you don't have metabolic abnormalities" (Ubelacker, 2013).

"We can reverse the childhood obesity epidemic. It isn't some kind of unstoppable force" (Stobbe, 2013).

"You ask anyone with more than 50 pounds of weight to lose, it's not: 'Hey, I need to lose those last 5 pounds or 10 pounds to get in shape for bikini season.' It's 'I want to be able to get up off the floor. I want to be able to bend down and touch my toes. I want to be able to keep up with my kids or be around for my grandkids" (La Rose, 2014).

"This is the problem of our generation" (Italie, 2014).

"Now is not the time to take our foot off the gas and congratulate ourselves on a job well done. Just the opposite. Now is the time to fight even harder"' (Superville, 2014)

"We have a responsibility, as human beings, to do something, to save each other..." (Caruso, 2013).

"We are in such a predicament with obesity in this country that we have to put the pussy-footing measures to one side...It's time for the stick to come out" (Cheng, 2013).

These quotes illustrate a particular stance on obesity that is threaded throughout all the articles. That obesity is a huge problem; something that must be fought, changed, and stopped. The language used in these articles is helping readers to make sense of obesity, but it is not politically neutral (Howe, 1994). Language is being used here not simply to describe obesity, it is constructing and maintaining fatphobia. These quotes paint an image of fat people as people who 
are immobile and going to die soon, people who are problematic, and people who need to be fought, stopped, or changed.

Doctors were not only given the most space in the articles, they were also given the most power. The power to define obesity, the power to call it a "disease", and the power to decide how to "fight" it. One article focused on doctors needing to "get tougher" with patients about their weight (Stobbe, 2013). "The medical profession has issued new guidelines for fighting the nation's obesity epidemic, and they urge physicians to be a lot more aggressive about helping patients drop those extra pounds" (Stobbe, 2013). The article says doctors should calculate patient's BMI, and if your BMI indicates you need to lose weight, they should come up with a weight-loss plan and send you to counselling. Doctors are also encouraged to recommend weight-loss surgery to patients who are "severely obese". These guidelines are part of several important developments in the "fight against obesity", including the Food and Drug Administration approving more obesity-fighting drugs, and the American Medical Association labelling obesity as a disease (Stobbe, 2013). Doctors "need to get the message, just telling someone you need to push the plate away is not going to work for everyone" (Stobbe, 2013).

This medical discourse that gives power to medical practitioners is directly counter to large body of literature that suggests that harsh medical interventions about obesity do not lead to positive health outcomes. Fat patients often deal with being misdiagnosed or not diagnosed at all because medical professionals assume the only explanation for their symptoms is their weight (Harding \& Kirby, 2009; Hebl \& Xu, 2001). This medical neglect or malpractice can lead to higher rates of disease and death, which is not considered when obesity is linked with higher rates of disease and death. 
This was demonstrated by only one of the articles, which focused on weight bias in cancer care (Marchione, 2013). Obese people are less likely to survive cancer, and one of the reasons is that overweight people are undertreated because doctors do not base chemotherapy doses on size. Giving too little chemo significantly worsens the odds of survival. "There's little doubt that some degree of undertreatment is contributing to the higher mortality and recurrence rates in obese patients," said Dr. Gary Lyman, a Duke University oncologist (Marchione, 2013).

Aside from malpractice and neglect, there are also deeper psychological effects of the medical profession's obsession with weight. As body weight increases, the rate of health care delay and avoidance also increases (Drury \& Louis, 2002). Frequently experiencing stigmatizing situations is associated with more mental health symptoms, negative body image and lower selfesteem (Myers \& Rosen, 1999). Fat patients delay accessing health care and avoid doctors if they have gained weight since the last visit, have to get weighed when they go in, have been or fear being told to lose weight, and if they need to undress in the providers office (Drury \& Louis, 2002).

The articles focused on weight-loss surgery downplayed the risks of obesity surgery. The medical discourse promoted weight loss surgery as "generally safe for teens" when 55 of the 242 teenagers participating in the study experienced complications, and 19 of the 55 experienced major complications, including injury to internal organs (Tanner, 2013). These numbers are not statistically insignificant, and we need to question why they are being presented as such.

There were even "a few deaths" after obesity surgery, although the risk was "no greater than for other major operations" (Tanner, 2013). Again the statement of risk only focused on the physical, and there are many more psychological and social elements interlocked with weightloss surgery than other major operations. Weight-loss surgery is differently motivated than other 
major operations, and downplaying "a few deaths" allows a medical discourse to construct fatness as a life-threatening situation in the same way that other conditions prompting major surgeries are. No one should feel forced to suffer complications or die in the quest for thinness. The articles exclude any perspectives that suggest weight-loss surgery might be so popular because of the moral and aesthetic objections to fat bodies rather than any impact it could have on health. The focus on undergoing weight loss surgery for one's health conceals the fact that weight-loss surgeries are motivated by the experiences of social stigmatization, discrimination and marginalization that fat people experience on a daily basis.

Imagery was a powerful way that the medical discourse manifested itself. 26 images were of fat bodies in medical/surgical settings, often getting weighed, measured, or operated on.
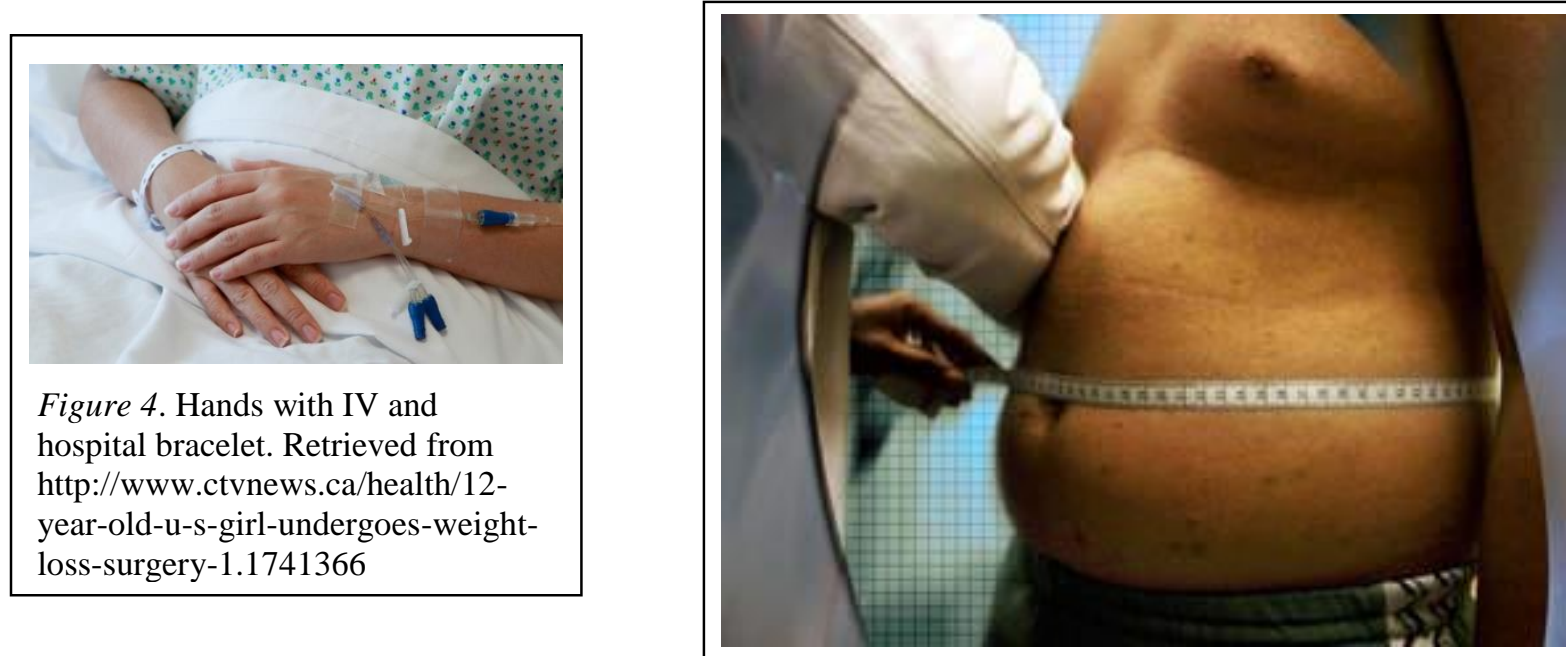

Figure 5. Doctor measuring waist. Retrieved from http://radio.foxnews.com/2013/11/04/teens-seekingobesity-surgery-often-have-many-health-issues/ 


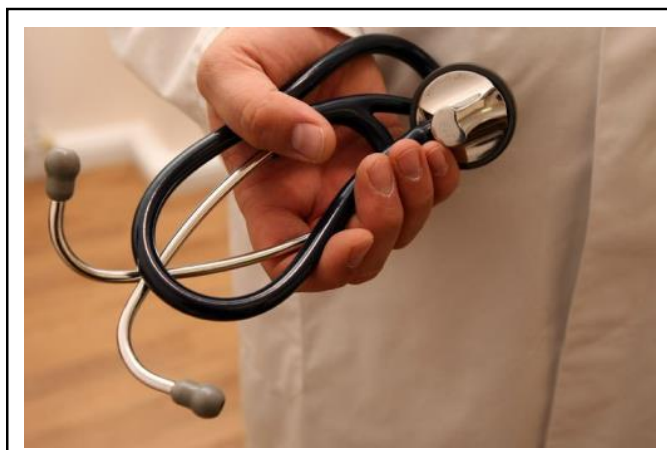

Figure 6. Doctor holding stethoscope. Retrieved from

http://globalnews.ca/news/966590/

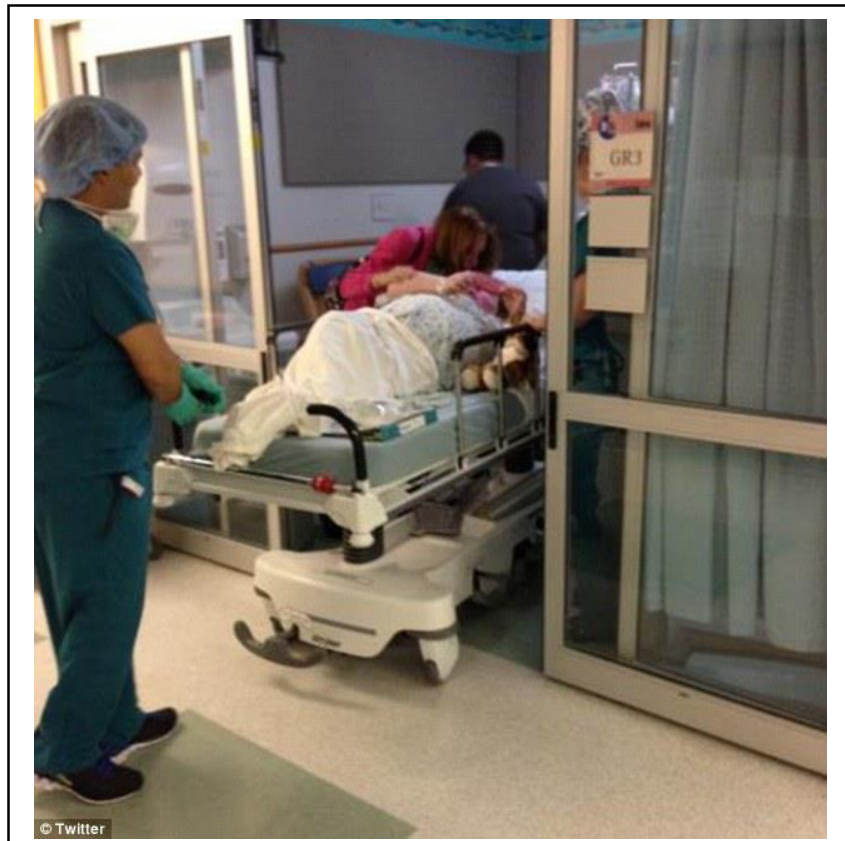

Figure 9. Alexis Shapiro getting wheeled into surgery. Retrieved from

http://www.dailymail.co.uk/news/article-

2586146/Alexis-Shapiro-goes-life-changing-gastricbypass-surgery-help-curb-enormous-appetite-causedrare-disorder.html
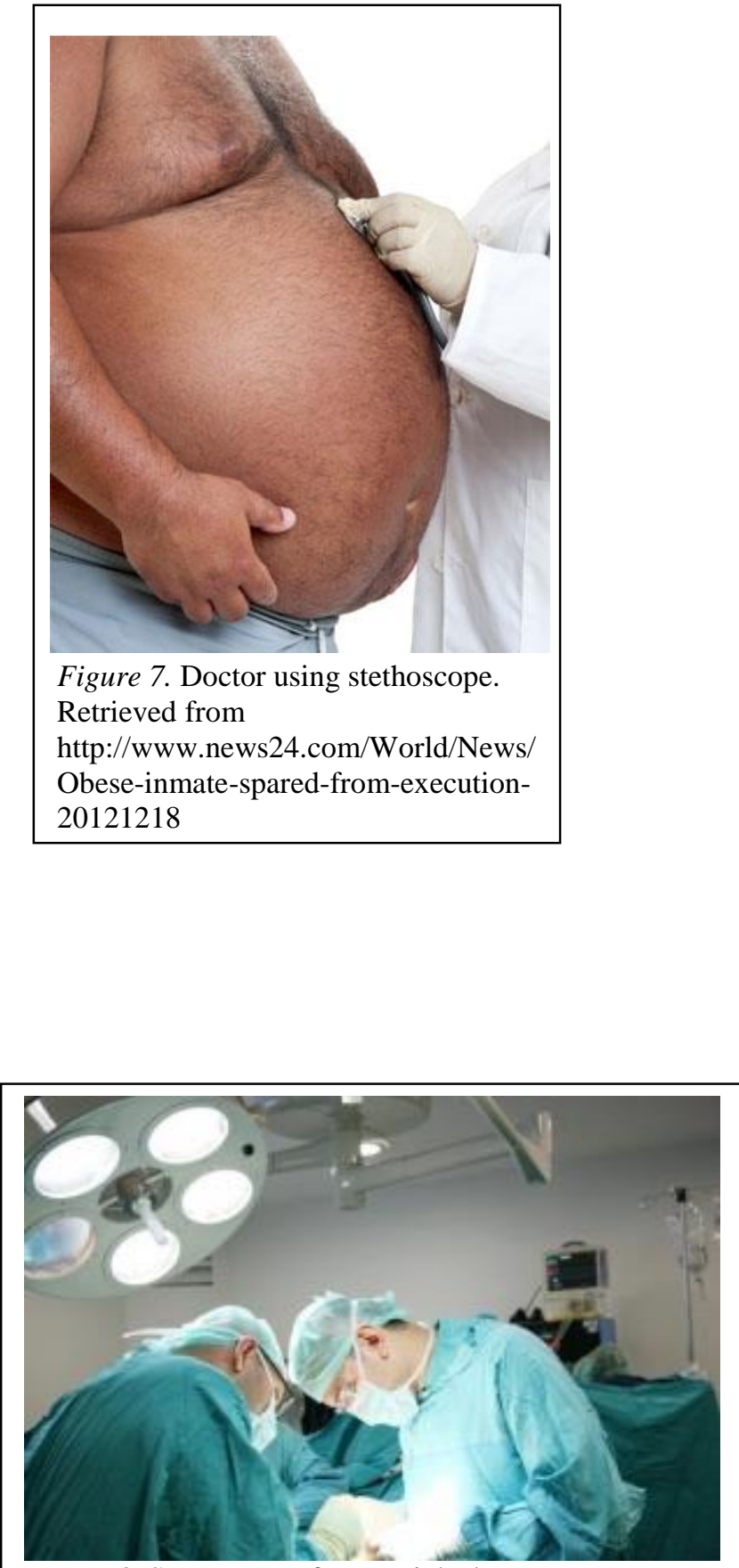

Figure 8. Surgeons perform weight-loss surgery.

Retrieved from

http://www.roundnews.com/health/medicine/2320texas-girl-with-medically-induced-obesity-to-havesurgery-in-ohio.html 
These images associate fat bodies with medical situations, with illness, with disease, and with death. These bodies are not out enjoying themselves or enjoying life, they are in hospitals, in doctors' offices, needing to be measured, weighed, operated on, and scrutinized. The prevalence of these images contributes to a medical discourse which legitimizes medical experts to "intervene". Showing only body parts, we see no humanity in the medical images. We only see something that needs to be "fought", "tackled", and "solved".

What the dominant medical discourse obscured with its focus on "expert" voices and sensationalized headlines about obesity, was that the "benefits" of medical interventions to obesity are unproven. The articles focused on weight-loss surgery had small sample sizes, or were short-term studies without longitudinal follow-up (Neergaard, 2013; Tanner, 2013; Tanner, 2013). "More long-term evidence on risks and benefits is needed to determine if obesity surgery is an appropriate way to treat...patients" (Tanner, 2013). All the articles contain an obligatory mention about how long-term effects have yet to be studied, and they don't know if the positive results will continue for patients in the future. Yet the Canadian media keeps producing sensationalized headlines and articles about weight-loss surgery being a solution to obesity, which is something that simply isn't known yet, even if the "benefits" do ultimately end up outweighing the significant risks. It is significant that various medical interventions are being normalized as a way to "deal with" obesity. A discourse is operating here that minimizes the serious and negative complications that arise from surgical and treatment interventions. We need to consider who benefits from this framing of obesity, and how.

The medical discourse also individualizes the focus on obesity. It shifts the gaze onto the individual, and taking the correct steps to change individual fat bodies. It obscures the complex 
systemic and structural issues that shape the realities of fat people. I will discuss how this individualizing gaze interacts with another discourse in the next section.

\section{Economics}

It is problematic that low-income children and families are identified as the highest risk for obesity, yet the focus was almost exclusively on eradicating obesity, not poverty. The responsibility is downloaded onto individual families and mothers with statements such as “...parents really need to be the commanders of their own ship and manage the food environment for their kids at home" (Italie, 2014). Systemically reducing poverty and making sure low-income people have access to health care in the U.S. would do more to reduce obesity and ill health than initiatives targeted at obesity alone. However, as stated in the literature review, neoliberalism seeks to blame the problem on individuals, rather than focus on wider systemic change (Herndon, 2002; Stubblefield, 2007).

When you dig deeper into the articles, it becomes noticeable that obesity may not even need to be "tackled". Articles focused on childhood obesity rates identified that they have been flat for decades and now are starting to decline (Italie, 2014; Stobbe, 2013). This information is directly counter to the mass hysteria about ever-growing, epidemic obesity rates. Even taking into account flat or declining rates, the "experts" are quick to warn that the "problem" is not going away, so we mustn't relax our vigilance. However, if we have seen a flat rate of obesity that is now slowly beginning to decline, I see no stronger evidence that the "problem" may not be as epidemic as we have been led to believe. Therefore we need to start to question who and what is benefitting from the continued promotion of the "war on obesity".

The question "who benefits?" reveals a powerful economic discourse that is shaping and driving all of the articles. What is ultimately made clear through this discourse analysis is that 
the "war on obesity" has nothing to do with concern for fat peoples' health and everything to do with the cost of obesity and who has the power to profit.

\section{Diet and Exercise}

More than half of the articles were focused on diet and exercise. These "lifestyle changes" were touted as being the key to weight-loss. We do not make objective decisions about food when we stand in the aisle of a supermarket, we are influenced by discourses infused with political, cultural, and rhetorical power (Miller, 2012). When we focus on the promotion of certain kinds of foods, and the demonization of others, it is important to realize that we are dealing with the concentration of power and wealth in the hands of the few. "The food system has become the focus of intensive corporate concentration, economic power, and the systematic dismantling of community and democratic ownership over food and agriculture" (Miller, 2012, p. 243). The same corporations that profit from the production and dissemination of "junk" foods, are often also the ones that are now destroying agricultural systems to bring you "organic", "free-range", "gluten-free", "sugar-free", "low-fat". And all for a price.

One article focused on a government initiative to put calorie-counts on restaurant menus (Babbage, 2014). This again focuses on individuals and influencing (and shaming) individual food choices instead of asking bigger questions about who profits from making those foods available in the first place. Restaurant chains are players in a globalized, capitalistic food system.

Two articles focused on soda and sugary drinks specifically. The first discussed New York City's Board of Health's ban on large-sized, high-calorie beverages, and the second looked at implementing a 20\% soda tax to cut obesity rates in Britain (Caruso, 2013; Cheng, 2013). In New York, the attempt to ban sugary drinks has been seen as an "overdue attack on one of the 
primary contributors to a national obesity epidemic" (Caruso, 2013). A spokesperson in Britain for the National Obesity Forum proposed that the government fine companies if they exceed a certain amount of sugar in their foods and drinks. "Companies should be coerced with fiscal measures rather than punishing the consumer with taxes" (Cheng, 2013). Either way, there are financial and economic benefits to regulating what people eat. If soda is banned in New York, which beverage companies stand to gain enormously by producing the drinks that will take sodas place? Whether a soda tax is levied in the U.K., or corporations are fined, the government still receives a huge financial return from the discursive construction of obesity as "dangerous" and something that must be dealt with.

The soda articles represent Foucault's ideas about the connection between health and bio-power. Here we see a form of social control being exercised, with a ban or a tax being a disciplinary practice. This promotes discipline for those who fail to achieve "good health" (Gastaldo, 1997). There is power inherent in the decision to regulate food and drink, and the aims and objectives of this power struggle are very visible (Foucault, 1978). It was very interesting that a higher level of government overturned the NYC soda ban, even going so far as to say that the ban was based on "clearly political or economic considerations rather than health concerns" (Caruso, 2013). Though this thought was not articulated beyond a single sentence regarding a soda ban, the framing of obesity in general has always been based on political and economic agendas rather than health concerns.

Richard Bress, a lawyer that challenged the NYC drink regulation is quoted in the article as saying, "For the first time, this agency is telling the public how much of a safe and lawful beverage it can drink. This is the government coercing lifestyle decisions" (Caruso, 2013). While I agree and find this troubling, I also think it is a failure to see only the drink ban as a way that 
the government is coercing lifestyle decisions of the public. For example, Michelle Obama is working very hard to coerce lifestyle decisions with her anti-obesity initiatives. The articles demonstrate that governments in North America are now supporting all sorts of anti-obesity initiatives, programs, and research. Are we not to see those forms of coercion in a negative way? I am left with questions about where the line gets drawn between coercive and positive change. When it comes to the obesity, the line between public and private when it comes to decisions that we make about our own bodies is becoming frighteningly blurred.

One article promoted Downsize Fitness, a gym geared to overweight people, which is making its debut in Canada (La Rose, 2014). Downsize Fitness focuses its efforts on individuals who have more than 50 pounds to lose. One of the owners of Downsize is quoted as saying “...when you're supported in a community where they're all going through the same thing, and the trainers have gone through it, you feel much more supported than if you're going to a gym and hoping it's going to work" (La Rose, 2014). However, Downsize Fitness did not open solely out of the goodness of their hearts and the desire to communally support fat people. The weight-loss and fitness industries are billion-dollar industries that command an immense amount of power and financial resources. Downsize Fitness is leaping on the bandwagon of fitness facilities seeking to meet a niche market and provide specialized services. “...these niche market facilities are easier to open, they're easier to operate, they're easier to get into, especially when you get into looking at franchises" (La Rose, 2014). They thrive on the medical discourse that focuses on individual change rather than systemic transformation. These business people are well aware of the economic power they stand to gain by capitalizing on anti-obesity messages that drive people to want to change their bodies. 


\section{Medical Weight-Loss Initiatives}

The economic discourse became extremely clear when analysis revealed the contradictions between the articles. The diet and exercise articles triumph "lifestyle changes" as the key to fighting ever-rising obesity rates which are at "epidemic proportions". There are many powerful players that stand to benefit from this framing of obesity. However, the surgery articles contradict this and state that lifestyle changes, including dieting and exercise, rarely work for fat people (Neergaard, 2013; Tanner, 2013). There is just as much power to be gained from framing medical interventions as the solution. The framing of obesity and the directions of obesity interventions are heavily influenced by the American Obesity Association (AOA) (Harding \& Kirby, 2009). As discussed in the literature review, the AOA is sponsored by The American Society for Metabolic and Bariatric Surgery, International Federation for the Surgery of Obesity, Jenny Craig, Inc., Knoll Pharmaceutical Company, Weight Watchers International, Inc., Slimfast, Medeva Pharmaceuticals, and others (Harding \& Kirby, 2009). The way the AOA frames obesity makes commercial weight-loss programs, pharmaceutical companies, and doctors who perform weight-loss surgery economically and discursively powerful. The articles seamlessly put forth two separate solutions for dealing with obesity. Both solutions draw power from being underpinned by the same economic discourse.

Weight-loss drugs were also mentioned in the articles as a potential solution. However, weight-loss drugs fail to achieve permanent weight loss and can result in negative health consequences, especially since the governmental agencies responsible for regulating weight-loss drugs have a history of not protecting consumers from dangerous drugs ("NAAFA Policies: Weight-Loss Drugs", n.d.). This was seen in the article about the weight-loss drug Meridia, where the B.C. Supreme Court ruled that a class-action lawsuit against the makers of anti-obesity 
drug Meridia could go ahead (“Class action lawsuit”, 2013). In 2009, worldwide sales of Meridia were over \$300 million, but the drug has caused some people dire health effects, including heart attacks and strokes. The lawsuit will examine whether the drug companies recklessly or negligently breached a duty to warn patients about harm from the use of Meridia ("Class action lawsuit", 2013). Even though the drug is dangerous, and the makers of Meridia now have to pay for a legal battle, they have already economically benefitted and made hundreds of millions of dollars in profit. There is no motivation to protect obese people or consumers of weight-loss solutions when obesity is discursively constructed in a way that makes the quest for thinness so profitable. Obesity researchers and drug manufacturers profit from inadequately tested weightloss drugs, and the economic discourse allows them to continue to do so (Harding \& Kirby, 2009; "NAAFA Policies: Weight-Loss Drugs", n.d.).

\section{Travel}

Another way that the economic discourse manifested itself was in articles focused on obesity and travel. A Samoa airline is motivating passengers to lose weight by pricing tickets based on the weight of the person, not the price of the seat (Sagapolutele \& Perry, 2013). Chris Langton, Samoa Air's Chief Executive stated that "planes are run by weight and not by seat...the plane can only carry a certain amount of weight and that weight needs to be paid. There is no other way" (Sagapolutele \& Perry, 2013). Langton had tried to implement this idea at other airlines, but they "considered weight as too sensitive an issue to address" (Sagapolutele \& Perry, 2013). Samoa's General Director Health, Palanitina Toelupe, feels that the airline's pricing structure is a great way to promote weight loss and healthy eating, and the flights being too expensive for larger people can become part of a larger strategy for addressing weight issues (Sagapolutele \& Perry, 2013). Some free flights have been given to regular customers who have lost weight. With 
Samoans having one of the highest rates of obesity in the world, Samoa Air is likely to profit greatly from this new pricing scheme.

The second article recounted the story of Kevin Chenais, a 500-pound man from France who was in the U.S. for many months receiving medical treatment for genetic and hormonal illnesses and imbalances that cause his obesity (“Obese Frenchman”, 2013). When Chenais' treatment was complete, British Airways refused to honour his return ticket because his size made him unfit to travel. When seeking other options, many plane, train and cruise ship companies all refused him transport. Eventually, Virgin Atlantic airlines flew Chenais to London, where he then boarded an ambulance which drove onto a ferry crossing the English Channel. The ambulance then completed a 740 kilometer drive to Chenais' home. The travel solutions available to them cost the Chenais family an incredible amount of money ("Obese Frenchman”, 2013).

Discussions about fat travellers inevitably lead back to a focus on dangerously rising obesity rates, rather than a focus on accommodating larger passengers. Lack of space on airplanes is classified as a fat person's problem, the implied solution to which is weight loss. Travel companies and corporations can capitalize on this individualization by charging large passengers more instead of removing barriers to travel.

The idea that obese people themselves are to blame was supported by multiple photos showing fat bodies being unable to fit comfortably into airline seats. 


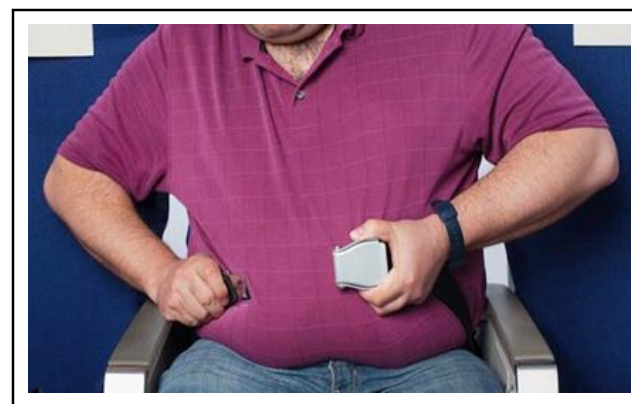

Figure 10. Man on airplane tries to buckle seatbelt. Retrieved from http://pacific.scoop.co.nz/2013/04/media -frenzy-over-samoan-airline-after-newpay-for-weight-policy/

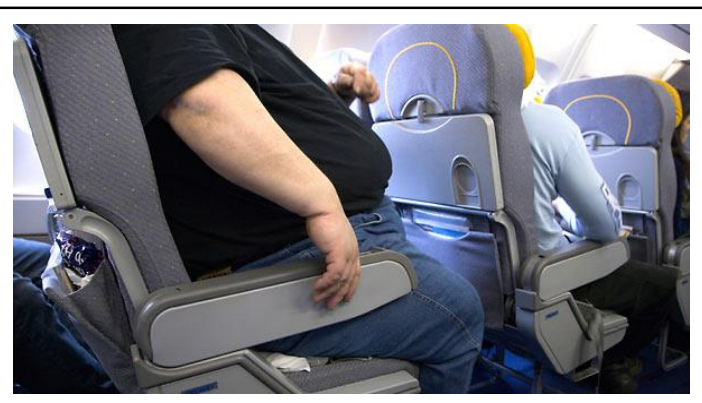

Figure 11. Man in airplane seat. Retrieved from http://www.dailyfinance.com/on/airlinestarts-charging-passengers-by-the-pound/

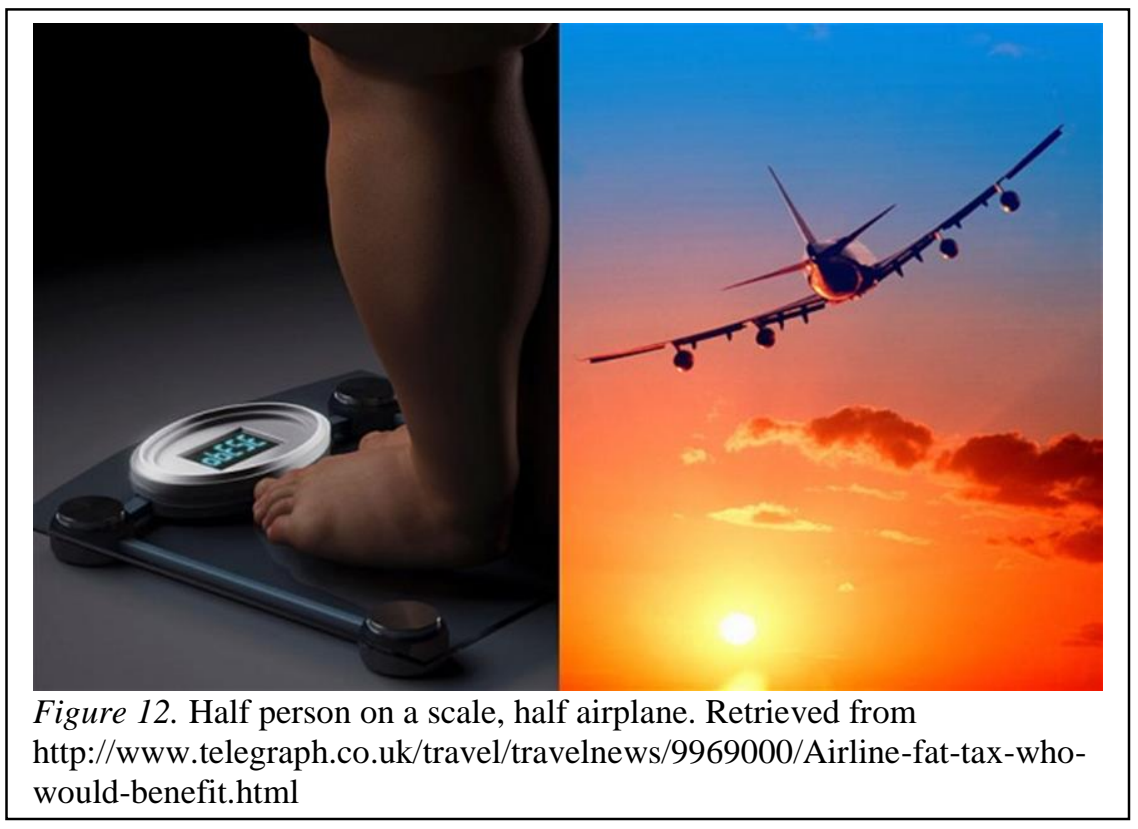

In fact, companies are actively making travel more inaccessible in order to gain economic advantage. Over the last two decades, airline seats have gotten smaller, with the space between seats decreasing by about $10 \%$. Struggling airlines are constantly working to make seats smaller and add more seats, increasing their revenue (Mouawad \& White, 2013). The discourses underpinning the obesity epidemic give the airlines the power to do this, as the discourse is 
framed so that shrinking seat sizes instantaneously become about individual fat travellers and their need to lose weight, instead of airline inaccessibility.

Every solution put forth to combat obesity was economically motivated. The economic discourse is extremely successful at shifting the gaze and the blame onto individual obese people, and making weight-loss their sole responsibility. This discourse completely and conveniently obscures the fact that obesity is not a fact. It has been discursively constructed in a way that gives power to certain structures, industries, and bodies. The construction of obesity is really about power, and the dominant groups that stand to gain from a negative framing of fat bodies. 


\section{CHAPTER 6. DISCUSSION}

The discourses operating in the articles were powerful, well-constructed, and were accepted as truth. This chapter will question some of the assumed truths, and discuss implications for social work educators and professionals.

\section{Diet, Exercise, and Michelle Obama}

Michelle Obama is a key figure in the fight against obesity, and she profits economically and politically from taking this stance. She also is an agent in individualizing obesity, and making it about "education" instead of "change". Nutritional information is readily available, and I believe that people can be trusted to understand which foods are "healthy" and which foods are not (if we are accepting that paradigm). It would be more important to redistribute the time, money, and energy that is currently being devoted to "raising awareness" and Michelle Obama's "Let's Move!" campaign into removing systemic barriers that make eating healthily challenging for many people and families. It is fascinating to hear Michelle Obama discuss how families need to move and cook at home, when she lives in the White House and has an arsenal of staff at her beck and call. I see no awareness of her privileged position in anything Michelle Obama ever says about obesity. Anti-oppressive practice would require Michelle Obama to think about her social location, the ways in which she is privileged and oppressed, and to be mindful of the space she is taking up with regards to these issues and the impacts her voice is having.

The kind of "healthy eating" and "regulated portions" that Michelle Obama is promoting are neither a successful nor a healthy weight control practice. Dieting blurs the line between pathology and "normal" eating, even though this is hidden behind a rhetoric of improving one's health (Heyes, 2006). Additionally, diets do not achieve long-term weight loss for the vast majority of people (Bacon \& Aphramor, 2011; Harding \& Kirby, 2009). Dieting is associated 
with weight gain over time and can lead to a variety of negative health consequences (Bacon \& Aphramor, 2011; Harding \& Kirby, 2009; Bacon \& Aphramor, 2011). Research shows that dieting reduces bone mass, and increases psychological stress and cortisol production (Bacon \& Aphramor, 2011). Losing weight through dieting and then regaining it (a process known as weight cycling) leads to increased mortality, increased risk of cardiovascular disease, stroke, and diabetes (Harding \& Kirby, 2009). In fact, many supposedly obesity-related illnesses have been shown to be dieting-related illnesses (Harding \& Kirby, 2009).

Lifestyle modification involving diet, exercise, and other behaviour changes reliably induces short term weight loss, but $95 \%$ of individuals are unable to maintain that for more than 5 years (Bacon \& Aphramor, 2011). Unfortunately, most studies that promote diet and exercise changes rarely follow up with participants beyond the first year, they merely conclude that the results were successful (Harding \& Kirby, 2009). A weight-focused paradigm, is not only ineffective at producing thinner, healthier bodies, but it is also damaging. It contributes to food and body preoccupation, reduced self-esteem, eating disorders, and weight stigmatization and discrimination (Bacon \& Aphramor, 2011).

As discussed in the literature review, public health campaigns like "Let's Move!" that focus on childhood obesity often do not provide constructive and blame-free ways to address weight, and can be detrimental to children's mental health (Davison \& Birch, 2001). These campaigns often contribute to body dissatisfaction, dangerous dieting, low self-esteem, and increased weight-bias amongst children and adolescents (Davison \& Birch, 2001; "NAAFA Newsletter", 2010). Media and cultural obsession with achieving a certain weight often does little or no good and may actually undermine motivation to adopt exercise and other healthy 
lifestyle habits ("NAAFA Newsletter", 2010). The National Association to Advance Fat Acceptance (NAAFA) spoke about "Let's Move!" as a campaign that turns fat kids into targets,

When our First Lady said that we have to wipeout childhood obesity in one generation, she essentially gave permission to everyone to condemn children with higher body weights. How this translates in real life is that these children experience more ridicule, more teasing, more bullying, and the perpetrators feel justified in their actions because after all, the First Lady said these kids have to go. (Herzog, 2011)

\section{Weight Loss Surgery}

The most surprising part of my research was how prevalent weight-loss surgery was in the articles. The discourses position weight-loss surgery as the best solution, despite the tremendous amount of deaths and severe complications associated with them and a lack of conclusive evidence that they improve health ("NAAFA Policies: Weight Loss Surgery", n.d.). Over $40 \%$ of weight-loss surgery patients have complications within three years, and one in 50 people die within 30 days of undergoing weight-loss surgery ("NAAFA Policies: Weight Loss Surgery", n.d.). The problems of fat discrimination and stigma and the psychosocial suffering experienced by fat people are best challenged through political activism and cultural change, rather than forcing fat people to mutilate their bodies. Fatness goes beyond being a health problem, it is a social problem, and fat issues cannot be solved by inflicting medical solutions on those experiencing a social problem. "Indeed, some fat activists see weight loss surgery as a form of genocide against fat people, the ultimate example of how the 'war on fat' is indeed taken out on fat people (Farrell, 2011, p. 169).

Despite all of the above, weight loss surgery is increasingly popular. The propaganda about weight-loss surgery, coupled with the severe and unrelenting stigma that fat people experience helps to explain why so many fat people are "choosing weight loss surgery, despite 
its known risks and its unknown outcomes" (Farrell, 2011, p. 169). Farrell (2011) believes that it will take increasing fortitude for fat people to resist going under the knife.

\section{Doctors, Representation and Identity}

The article that focused on doctors giving obese patients less chemotherapy than they needed, was the only article that used the term "weight bias" (Marchione, 2013). It notable for being the only article that acknowledged that stigma and negative biases towards fat people play a role in their health and in the way that obesity is framed.

The articles favoured quoting various doctors and "obesity experts" (whatever that means). Anti-oppressive practice centres people as the experts of their own experiences, yet no articles turned to fat people as the "experts". 4 formerly fat people were quoted in articles, 2 who were lauding losing weight through exercise, 1 who was discussing how great weight-loss surgery was, and 1 who was praising the tougher guidelines doctors were given to follow (La Rose, 2014; Stobbe, 2013; Tanner, 2013). In all 20 articles, only one currently fat person was quoted, a woman who had had breast cancer and was quoted saying how fortunate she was that her doctor gave her the correct dose of chemo therapy (Marchione, 2013).

This silencing of fat voices in a dominant sphere has an impact on identity formation. Fat peoples own experiences and interpretations of social life found no expression in these Canadian Press articles. When members of subordinated groups do not find themselves reflected in literature, the media, formal education, or are represented in a highly distorted fashion, they are rendered invisible by the dominant group that is also marking them as different (Mullaly, 2002). Many fat activists discuss the contradictory feelings of living in bodies that are both invisible and hyper-visible at the same time. McEwan (2013) writes, 
It is a jarring and anxiety-inducing experience to go from being someone whose body dehumanizes her to the point of nonexistence in most of her daily life, ignored by salespeople and bartenders and people walking directly towards me, to someone whose body makes her highly visible, obliging me to be aware of an unusual number of scrutinizing stares. (para. 3).

Owen (2008) questions how fat people can feel invisible, when fat bodies are hyper-visible, even a public spectacle. Her take is that the sense of invisibility nearly all fat people have felt is symbolic. "It is not our bodies, per se, that are invisible; it is our needs, our individualities, our identities as legitimate social citizens, that are ignored or disregarded" (Owen, 2008, p. 121).

This simultaneous invisibility and being marked as different often causes an internalization of the dominant group's stereotyped and inferiorized images, which causes some oppressed people to act in ways that affirm the dominant group's view of them as inferior people, and will reproduce their own oppression (Mullaly, 2002). We saw this in the articles where formerly fat people were given a voice if they bought into the discourses the articles were promoting, and threw other fat people (and therefore also their former selves) under the bus.

\section{Photos}

The most notable thing that the photos yielded was that none of the photos of fat bodies had heads. 14 of the images pictured fat bodies out and about, walking, travelling, and eating. Most of these images were of racialized, female bodies. 


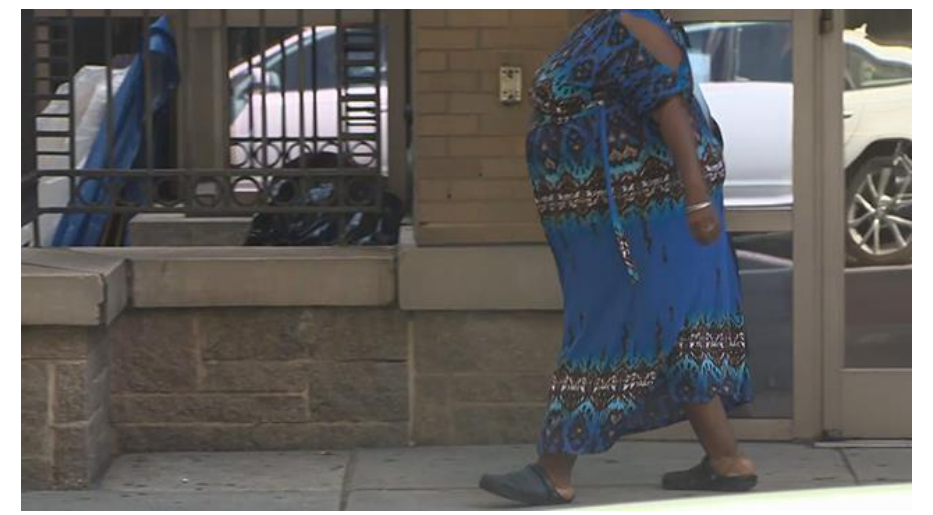

Figure 13. Woman in blue dress walking. Retrieved from http://globalnews.ca/news/1005634/benign-obesity-a-mytheven-if-blood-pressure-cholesterol-healthy-study-says/

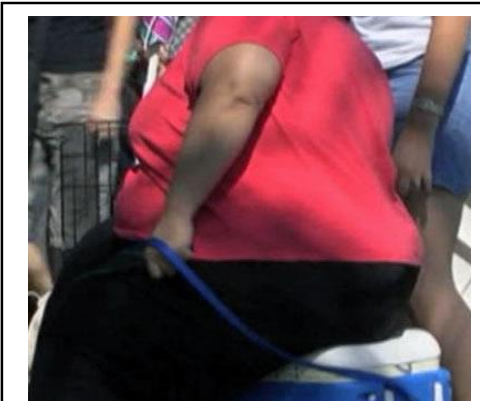

Figure 14. Woman in pink shirt sitting. Retrieved from http://www.cbc.ca/news/health/ obesity-now-recognized-as-adisease-1.1320011

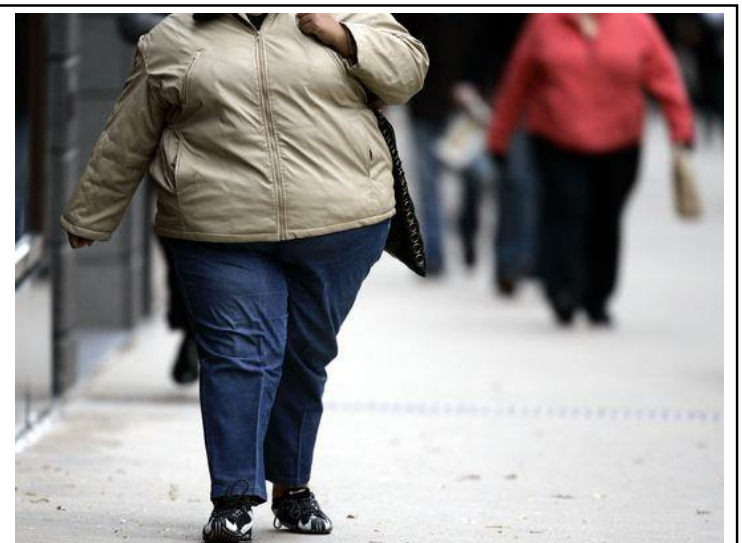

Figure 15. Person in tan jacket and jeans. Retrieved from

http://www.usatoday.com/story/news/nation/201 3/06/04/obesity-surgery-diabetes/2389487/

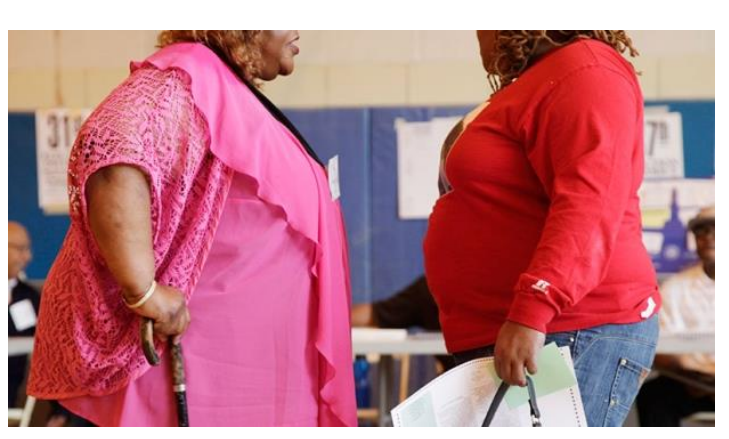

Figure 16. Two women talking. Retrieved from http://www.ctvnews.ca/health/healthheadlines/obesity-surgery-helps-treat-diabetesbut-carries-risks-study-1.1311718

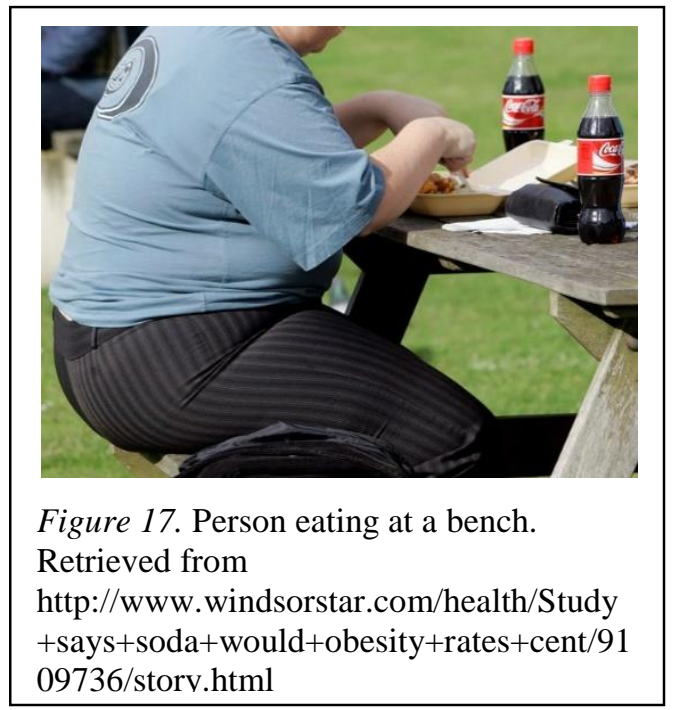


The following picture is particularly telling, where a face, and therefore humanity is bestowed on the thin person who is measuring and scrutinizing the fat person, but the fat person has no identity.

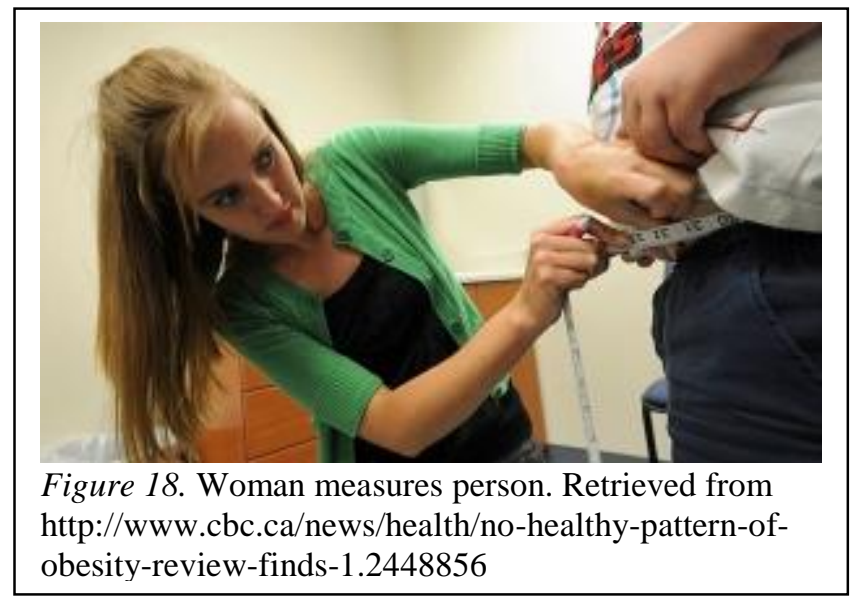

It is notable that so many of the headless fat bodies were racialized, and that most of them were female. This trend speaks to whose bodies are considered public property to be used and commented upon, to be photographed secretly, and who is respected as being an autonomous person. Racism and fatphobia are clearly intersecting in the images that were presented in the articles.

Charlotte Cooper, a prominent fat activist, has written about what she calls the "Headless Fatty" phenomenon. "Every hand-wringing article about...obesity seemed to be accompanied by a photograph of a fat person, seemingly photographed unawares, with their head neatly cropped out of the picture" (Cooper, 2007, para. 1). Fat people in news journalism are presented as objects, symbols, or a collective problem. We are talked about, we are not talked to unless we "play the game and parrot oppressive, self-hating, medicalized views about fat" (Cooper, 2007, 
para. 2). This was seen clearly in my earlier analysis of whose voices and opinions were represented in the articles. Cooper (2007) writes,

As Headless Fatties, the body becomes symbolic: we are there but we have no voice, not even a mouth in a head, no brain, no thoughts or opinions. Instead we are reduced and dehumanized as symbols of cultural fear: the body, the belly, the arse, food. There's a symbolism, too, in the way that the people in these photographs have been beheaded. It's as though we have been punished for existing, our right to speak has been removed by a prurient gaze, our headless images accompany articles that assume a world without people like us would be a better world altogether. (para. 3).

The fat people in the photos accompanying the Canadian Press article often look like they have been photographed without their knowledge or consent. When did this kind of surveillance become normalized for people who have fat bodies? Fat people are already the victims of surveillance medicine, and targeted public health and education campaigns, but now images of us are being taken and being produced and reproduced outside our control. When we see these Headless Fatty images we need to think about how the picture was taken, the message it was used to convey, how that message relates to the person in the image, and who that person might be (Cooper, 2007). The dominant discourses discovered in the article feed on the cultural fears that these images produce, and the symbolism that they are assigned. When no one wants to be those bodies, the solutions presented have great power and economic benefits.

\section{Implications for Social Work}

The Stobbe (2013) article framed doctors as sympathetic figures. "I feel for these guys," said Dr. Tim Church, a researcher at Louisiana State University’s Pennington Biomedical Research Center. "They have patients who come in and ask them about the latest fad diet. They're not trained in this stuff and they're not comfortable" (Stobbe, 2013). The article makes the assumption that the solution to this discomfort is to train doctors to be harsher about weight, recommend weight-loss surgery, and to send fat patients to a counsellor. This article makes an 
important link to counsellors who could also potentially be social workers. If we are encouraging fat patients to see a social worker, how do we know that the social workers are "comfortable" with this topic? The lack of fat discussion in social work education can leave social workers just as unprepared to handle weight issues as doctors, presuming that weight is something the patient would even be concerned about if they weren't being coerced into counselling!

I have seen a lot of misunderstanding and discomfort when I discuss my research topic and why I believe it is important. Yet social workers are also supposed be at the helm of the fight against obesity. Social workers are expected to support federal anti-obesity initiatives, assist in research, treatment options, and policies to end this "public health issue" ("Social Workers and their role", n.d.).

As the University of New England says on their website,

Individuals who are seeking a master's in social work may not immediately think their jobs will deal with obesity; however, as the issue is becoming a growing concern across the country, social workers may find that it is their job to help. Social workers can do their part to end the obesity epidemic in a variety of ways, from spreading awareness in schools to advocating for new policies that will promote healthier lifestyles. (Para 1.)

Eliadis (2006) has written an article discussing the role of social work in the childhood obesity epidemic. Her article frames social workers as essential in treating childhood obesity. Social workers should use systems theory to work with a child and their family to address lifestyle issues that need to be changed (Eliadis, 2006). Social workers should also use a strengths-based perspective to empower the child and their family to create a successful atmosphere for combatting obesity (Eliadis, 2006). Social workers also need to be "culturally competent" and "culturally sensitive" to address food issues (Eliadis, 2006). This overly simplistic article does not incorporate a critical lens, nor does it align itself with anti-oppressive principles, yet it is one of the only academic articles that discusses obesity and social work. 
The VCU Medical Centre has made available a slideshow created by a MSW discussing obesity from a supposedly social work perspective (Dunn, n.d.). Dunn (n.d.) discusses the correlation between obesity and depression, the role of the family in obesity, and the cost of obesity. She proposes CBT and support groups to treat obese patients (Dunn, n.d.).

There are many examples of the ways social workers are already coming into contact with obesity. In Ontario, you must meet with a social worker before being considered for bariatric surgery ("Social Work", 2010). Our profession is also starting to question whether obesity is as bad as child abuse, and whether parents should lose custody of their children if they are obese (Conley, 2011). "State intervention may serve the best interests of children with lifethreatening obesity, comprising the only realistic way to control harmful behaviours," argues Dr. Ludwig, an obesity expert (Conley, 2011, para. 2). Indeed, in the U.K., social workers have already begun to apprehend obese children (Davis, 2013).

Most of the literature that exists regarding social work is not from an anti-oppressive, anti-racist, or critical lens. It is troubling that there isn't more focus on critiquing the stigma and discrimination of fat bodies. Further, none of the above social work literature focuses on the discursive constructions of the obesity epidemic, it is accepted unquestioningly as truth. Friedman (2012), in her article "Fat is a Social Work Issue", recognizes the flaw in this,

As social workers, we know that "common-sense" logic has often led to appallingly bad policy. Indeed, as members of the social work profession, we are aware that stigma, discrimination, and misrepresentations of populations... have been responsible for entrenched structural hatred. We need to extend our analysis, and our efforts, to engage with the obesity epidemic as similarly flawed and dangerous. (p. 9)

Social workers are socialized into the dominant culture just like everyone else (Mullaly, 2002). Social workers are not immune to carrying out oppressive acts, especially within social service agencies that often view social problems narrowly and "define them in terms of personal 
deficiencies, dysfunctional families, and inferior cultures" (Mullaly, 2002, p. 93). Original conceptualizations of social work saw the profession as committed to the regulation of poor people, who were considered to be the "dangerous classes". These classes needed to be reformed in order to reduce deviance, disease, and chaos and to advance civilization (Mullaly, 2002). This echoes the influence of the Eugenics movement that I discussed in the literature review. Obesity is seen as a hindrance to societal advancement. Social work employees are expected to treat and reform their clients, and when it comes to obesity we have specific dominant understandings about the ways in which this is to be carried out.

Social workers need to be careful about reproducing these oppressive practices that underpin the history of our profession (Mullaly, 2002). This research shows that social workers need to be especially aware of gendered power relations, mother blame, and medical and economic influences on the construction of obesity. We need to search for alternative and antioppressive ways to address obesity issues. One alternative to mainstream understandings of the obesity epidemic that challenges weight-focused and weight-loss paradigms is the Health At Every Size (HAES) movement. HAES encourages body acceptance as opposed encouraging weight loss. Bacon \& Aphramor (2011) found that body image has a much bigger impact on health than body size.

...two equally fat women would have very different health out-comes, depending on how they felt about their bodies. Likewise, two women with similar body insecurities would have similar health outcomes, even if one were fat and the other thin. These results suggest that the stigma associated with being fat is a major contributor to obesity-associated disease. (p. 6).

Instead of counselling people to diet and follow an exercise regime to lose weight, social workers could draw on HAES principles to promote intuitive eating and encourage people to find pleasurable ways of being active (Bacon \& Aphramor, 2011). The goal is to increase peoples' awareness of their body and its responses to food and activities that promote well-being and self- 
care. There are dangerous trends emerging where physicians and other health professionals promote eating disordered behaviour and prescribe extreme diets to women who have high BMIs (Harding \& Kirby, 2009). The same behaviours that would classify a thin woman as having an eating disorder, are celebrated and applauded in overweight and obese women (Harding \& Kirby, 2009). Social workers need to educate themselves so that they do not promote the same kinds of harmful eating behaviours.

Social workers should critique the singular focus on the fat service users they see losing weight. We should be educated about fat issues and ways to practice that are gentle and acknowledging of people's bodies and experiences. There is a growing body of scholarly literature challenging the link between BMI, disease, and death, and we need to be aware of it as we practice. Most studies show that people who are overweight or obese live at least as long as "normal" weight people, and often longer (Bacon \& Aphramor, 2011). Most of the diseases that are listed as being a higher risk for overweight and obese people, are diseases where obesity is actually associated with longer survival (Bacon \& Aphramor, 2011). It is also important to note that every health condition linked to higher BMI is frequently found in people with lower BMIs as well (Burgard, 2009). The problem between picking a dividing line between "acceptable" and "unacceptable" BMIs is that it cannot be applied to individuals (Burgard, 2009). For any given BMI, there are people who are healthy and people who are not.

"As social workers, we must remember our history and be very suspicious of arguments that rely on the public good to justify the need for individual change" (Friedman, 2012, p. 10). We need to challenge the idea that encouraging our clients to lose weight and "manage their obesity" is work we are doing for individual and societal good. It can be very tempting to fall in with these discourses about the dangers of obesity and to assume that that the correct thing for 
social workers to do is join the "fight". However, doing this work "under the cover of kindness" does not enhance the rights of fat peoples nor challenge systemic discrimination (Margolin, 1997 in Friedman, 2012).

\section{Future Directions for Research}

Now that I have gained a deeper understanding of current obesity discourses in The Canadian Press and dominant ideas of the role of social workers in the "war on obesity", I feel that there are many directions for future research. The first would be to conduct a full critical discourse analysis of obesity discourses, drawing not just from media articles, but from advertisements, blogs, policies, literature, education initiatives, etc. The question "what is the discourse?" cannot be answered by The Canadian Press alone. The Canadian Press articles presented negative stereotypes about obesity, underpinned by mother blame, the medical model, and economic power relations, which I know are not the only discourses. My particular brand of fat activism centres on creating strong, intersectional, counter-discourses to dominant understandings of fatness, and I did not see that reflected at all in the literature. While I think that I will find the same discourses I found in the Canadian Press Articles in a broader critical discourse analysis, I also believe that casting a wider net for data would capture more nuances and delve more deeply into different kinds of discourses that are all struggling to gain a foothold.

There is also a need for more primary research on fat issues that does not center White, heterosexual, nuclear family experiences. There is a need for research that understands and focuses on the fluidity of fatness categories and how they interact with other forms of marginalization. 
The third direction for future research would be conduct primary research with social work practitioners. Through focus groups, researchers could gain understandings about where social workers sit with regards to fatness and how they do or do not come into contact with obesity issues. These focus groups could also be critical learning or teaching moments for practitioners.

Finally, another direction would be to conduct interviews with fat social work practitioners specifically. Social workers are not always on the treatment and disciplinary end of obesity issues, we often live in fat bodies as well. I am interested in hearing the ways that fat social workers' bodies impact their practice. We do not practice inside a box, and my interactions with service users are continuously shaped and constructed by my age, my style of dress, my gender, and my fat body. I am also looking to examine the way fat social workers see themselves being taken up (or not) as professionals, when fat bodies are associated with traits that are counter to what we consider to be professional traits. Fat people are perceived as significantly less desirable employees, and are seen as less professional, less competent, less productive, not industrious, disorganized, indecisive, inactive, and less successful (Larkin \& Pines, 1979). This is research I have proposed to undertake at a doctoral level. 


\section{CHAPTER 7. RECOMMENDATIONS AND CONCLUSION}

In conclusion, the Canadian Press yielded some significant discourses about obesity. The Canadian Press articles presented obesity as a major obstacle impeding societal progress, even as responsible for societal decline. However many of the articles and "experts" saw obesity as something that could be overcome with a great deal of collective, focused effort. The media is a major participant in discursive construction, helping to produce and define health problems and legitimize certain solutions (Holmes, 2009).

The articles had some contradictions in the way obesity was defined. Obesity was defined as something that was on the rise, had to be stopped, was a crisis, but simultaneously articles said obesity rates had been flat for decades and now were declining. Children, low-income families, and certain racialized groups were positioned as particularly at risk, but little was done to delve deeper into systemic reasons for this because individual parents and families were framed as responsible. The articles legitimized diet and exercise, surgery and drugs, doctors, education and raising awareness as ways to combat and reduce obesity rates. However, there were more contradictions around diet and exercise being presented as the most important solution, and surgery-focused articles saying that diet and exercise didn't work. Doctors, experts, researchers, surgeons, and specialists were given voices in these articles, they became the spokespeople for obesity, instead of fat people themselves. At the same time as the obesity issues were being individualized, the imperative for health became more than a personal focus, it became a national and international issue. All articles framed obesity as something that had to be "fought" “tackled" "dealt with" or "managed". Weight loss was the key to winning this war.

Based on these ideas, my recommendations are the following: 
1. Social work education needs to involve discussions of obesity, dominant discourses, counter discourses, Health at Every Size, and fat activism.

2. Critical fat perspectives training should be provided to practitioners in the field, particularly those that work alongside preventative obesity initiatives.

3. Social work educators and practitioners need to engage more with pop culture and the media as influential on our personal and professional lives.

4. More research about obesity and social work needs to be conducted to further develop the idea of fatness as a social work topic.

It is important for social workers, and the clients and communities that they work with to understand that fatness is not just a body size, it is linked to social inequality (Baines, 2011). As anti-oppressive social work practitioners and anti-oppressive educators, we have an ethical obligation to bring the trends that this MRP has found forward in education and in practice, until critical and anti-oppressive understandings of fatness are common knowledge for all people in our field. 


\section{REFERENCES}

12-year-old Texas girl with medically induced obesity has weight-loss surgery at Ohio hospital. (2013, March 22). Canadian Press. Retrieved from https://www.thecanadianpress.com/news_and_information.aspx?id=1600

Adam, B.D. (1978). The Survival of Domination: Inferiorization and everyday life. New York: Elsevier.

Agell, G., \& Rothblum, E. D. (1991). Effects of clients' obesity and gender on the therapy judgments of psychologists. Professional Psychology: Research and Practice, 22(3), 223229.

American medical association. (2013). Retrieved from http://www.amaassn.org/ama/pub/news/news/2013/2013-06-18-new-ama-policiesannual-meeting.page

Babbage, M. (2014, February 24). Ontario moving ahead with calorie counts on restaurant menus and menu boards. Canadian Press. Retrieved from https://www.thecanadianpress.com/news_and_information.aspx?id=1600

Bacon, L., and Aphramor, L. (2011). Weight science: Evaluating the evidence for a paradigm shift. Nutrition Journal 10(9), 1-13.

Baines, D. (Ed.). (2011). Doing anti-oppressive practice: Social justice social work. Fernwood Pub.

Baum, T.,Charles L., \& Ford, W. F. (2004). The wage effects of obesity: A longitudinal study. Health Economics, 13(9), 885-899. 
Blank, H. (2011). Big big love: A sex and relationships guide for people of size (and those who love them). New York: Celestial Arts.

Body Mass Index. (n.d.) In Wikipedia. Retrieved October 01, 2013, from http://en.wikipedia.org/wiki/Body_mass_index

Boero, N. (2007). All the news that's fat to print: the American "obesity epidemic" and the media. Qualitative sociology, 30(1), 41-60.

Boero, N. (2009). Fat kids, working moms, and the "epidemic of obesity": Race, class, and mother blame. In E. Rothblum and S. Solovay (Eds.), The fat studies reader (pp.25-36). New York: New York University Press.

Brown, I. (2006). Nurses' attitudes towards adult patients who are obese: Literature review. Journal of Advanced Nursing, 53(2), 221-232.

Burgard, D. (2009). What is "Health at Every Size"? In E. Rothblum and S. Solovay (Eds.), The fat studies reader (pp. 42-53). New York: New York University Press.

Carr Smyth. (2013, July 26). Obese inmate spared from execution by governor dies 'expected' death in US prison hospital. Canadian Press. Retrieved from https://www.thecanadianpress.com/news_and_information.aspx?id=1600

Caruso, D. B. (2013, July 30). Appeals judges say NYC's ban on big, sugary drinks at restaurants is unconstitutional. Canadian Press. Retrieved from https://www.thecanadianpress.com/news_and_information.aspx?id=1600 
Chastain, R. (2012, May 31). Suing for Airline Fatty Policy. Dances with Fat. Retrieved from http://danceswithfat.wordpress.com/2012/05/31/suing-for-airline-fatty-policy/

Cheek, J. (2004). At the margins? Discourse analysis and qualitative research, Qualitative Health Research, 14 (8), 1140-1150.

Cheng. M. (2013, November 1). Study says soda tax would cut obesity rates by 1.3 per cent in UK, W. Europe's fattest country. Canadian Press. Retrieved from https://www.thecanadianpress.com/news_and_information.aspx?id=1600

Class action lawsuit against anti-obesity drug Meridia can go ahead: B.C. court. (2013, September 18). Canadian Press. Retrieved from https://www.thecanadianpress.com/news_and_information.aspx?id=1600

Conley, M. (2011, July 13). Should parents lose custody of extremely obese kids? ABC News. Retrieved from http://abcnews.go.com/Health/parents-lose-custody-obesitychildren/story?id=14062898

Cooper, C. (1997). Can a fat woman call herself disabled? Disability and Society, 12(1), 31-42.

Cooper, C., (2007). Headless Fatties. Retrieved from http://charlottecooper.net/publishing/digital/headless-fatties-01-07/

Cramer, P., \& Steinwert, T. (1998). Thin is good, fat is bad: How early does it begin? Journal of Applied Developmental Psychology, 19(3), 429-451.

Davies, B. (2005). The (im)possibility of intellectual work in neoliberal regimes. Discourse: Studies in the Cultural Politics of Education, 26(1), 1-14. 
Davis, M. (2013, December 29). Social workers take children from families who overfeed them. Sunday Express. Retrieved from http://www.express.co.uk/news/uk/450907/Social-workerstake-children-from-families-who-overfeed-them

Davison, K. K., \& Birch, L. L. (2001). Weight status, parent reaction, and self-concept in fiveyear-old girls. Pediatrics, 107(1), 46-53.

Dictionary, O. E. (2008). Oxford English dictionary online. Oxford University Press, Oxford, UK http://www. oed. com.

Drury, C. A. A., \& Louis, M. (2002). Exploring the association between body weight, stigma of obesity, and health care avoidance. Journal of the American Academy of Nurse Practitioners, 14(12), 554-561.

Dunn, L. (n.d.). Obesity: The Social Work Perspective. VCU Medical Center. Retrieved from http://www.vcuhealth.org/cvccd/pdfs/Psychosocial\%20and\%20Financial\%20Implications\% 20of\%20Obesity.pdf

Eaton, D. K., Lowry, R., Brener, N. D., Galuska, D. A., \& Crosby, A. E. (2005). Associations of body mass index and perceived weight with suicide ideation and suicide attempts among US high school students. Archives of Pediatrics \& Adolescent Medicine, 159(6), 513-519.

Eberstadt (2009). Is Food the New Sex? Policy Review. 159.

Eliadis, E. E. (2006). The role of social work in the childhood obesity epidemic. Social Work, 51(1), 86-88. 
Ernsberger, P. (2009). Does social class explain the connection between weight and health? In E. Rothblum and S. Solovay (Eds.), The fat studies reader (pp.25-36). New York: New York University Press.

Fairclough, N. (1992). Discourse and Social Change. Cambridge: Polity Press.

Farrell, A. E. (2011). Fat Shame: Stigma and the Fat Body in American Culture. NYU Press.

Foucault, M. (1972). The Archaeology of Knowledge and the Discourse of Language. New York: Pantheon.

Foucault, M. (1979). Discipline and Punish: The Birth of the Prison. Translated by Alan Sheridan. New York: Vintage.

Foucault, M. (1980). The History of Sexuality, Volume I. New York: Vintage.

Foucault, M. (1985). The use of pleasure: The history of sexuality volume II. Penguin.

Friedman, M. (2012). Fat is a social work issue: Fat bodies, moral regulation and the history of social work. Intersectionalities: A Global Journal of Social Analysis, Research, Polity and Practice 1(1).

Gastaldo, D. (1997). Is health education good for you? Re-thinking health education through the concept of bio-power. In A. Petersen and R. Bunton (Eds). Foucault, Health and Medicine. London: Roudedge.

Gatens, M. (1996). Imaginary bodies: Ethics, power and corporeality. London; New York: Routledge. 
Guthman, J. (2009). Neoliberalism and the Constitution of Contemporary Bodies. ? In E. Rothblum and S. Solovay (Eds.), The fat studies reader (pp.25-36). New York: New York University Press.

Harding, K. and Kirby, M. (2009). Lessons from the fat-o-sphere: Quit dieting and declare a truce with your body. New York: Perigee Books.

Hartley, C. (2001). Letting Ourselves Go: Making Room for the Fat Body in Feminist Scholarship. In J. E. Braziel, Jana and K. LeBesco (Eds.), Bodies Out Of Bounds. Fatness and Transgression (pp. 60-73). Berkeley: University of California Press.

Health Topics: Obesity. (2013). Retrieved on October 01, 2013 from http://www.who.int/topics/obesity/en/

Hebl, M. R., \& Xu, J. (2001). Weighing the care: Physicians' reactions to the size of a patient. International Journal of Obesity and Related Metabolic Disorders : Journal of the International Association for the Study of Obesity, 25(8), 1246-1252.

Hendrix, K. S., Carroll, A. E., \& Downs, S. M. (2014). Screen Exposure and Body Mass Index Status in 2-to 11-Year-Old Children. Clinical Pediatrics.

Herndon, A. (2002). Disparate but disabled: Fat embodiment and disability studies. NWSA Journal, 14(3), 120-137.

Herzog, A. (2011, August 11). First Lady's Anti-Obesity Campaign Turned Heavy Children Into Targets, Group Says. CNS News. Retrieved from http://www.cnsnews.com/news/article/first-ladys-anti-obesity-campaign-turned-heavychildren-targets-group-says 
Heyes, C. J. (2006). Foucault goes to weight watchers. Hypatia, 21(2), 126-149.

Hill, A. C. (2009). Spatial awarishness: Queer women and the politics of fat embodiment.

Retrieved from http://etd.ohiolink.edu/view.cgi/Hill Adrienne.pdf?bgsu1257110459

Holmes, B. J. (2009). Media coverage of Canada's obesity epidemic: illustrating the subtleties of surveillance medicine. Critical Public Health, 19(2), 223-233.

Howe, D. (1994). Modernity, Postmodernity and Social Work. British Journal of Social Work. $24,513-532$.

Italie, L. (2013, May 30). Amid anti-obesity battle, should cupcakes, candy ever stand for C in picture books? Canadian Press. Retrieved from https://www.thecanadianpress.com/news_and_information.aspx?id=1600

Italie, L. (2014, February 2014). Study shows obesity drop among preschoolers, but why? A look at the mystery, or miracle. Canadian Press. Retrieved from https://www.thecanadianpress.com/news_and_information.aspx? $\mathrm{id}=1600$

Jorgensen, M., \& Phillips, L. (2002). Discourse analysis as theory and method. SAGE Publications.

Kent, L. (2001). Fighting Abjection: Representing fat women. In J. E. Braziel, Jana and K. LeBesco (Eds.), Bodies Out Of Bounds. Fatness and Transgression (pp. 60-73). Berkeley: University of California Press.

La Rose, L. (2014, January 3). Gym geared towards overweight people latest entry into specialty 
fitness market. Canadian Press. Retrieved from

https://www.thecanadianpress.com/news_and_information.aspx?id=1600

Larkin \& Pines (1979). No fat persons need apply: Experimental studies of the overweight stereotype and hiring preference. Work and Occupations, 6(3), 312-327.

Latner, J. D., \& Stunkard, A. J. (2003). Getting worse: The stigmatization of obese children. Obesity Research, 11(3), 452-456.

Lawrence, S., Hazlett, R., \& Hightower, P. (2010). Understanding and acting on the growing childhood and adolescent weight crisis: A role for social work. Health \& Social Work, $35(2), 147-153$.

LeBesco, K. (2004). Revolting bodies?: The struggle to redefine fat identity. Massachusetts:

University of Massachusetts Press.

LeBesco, K. (2009). Quest for a cause: The fat gene, the gay gene and the new eugenics. In E. Rothblum and S. Solovay (Eds.), The fat studies reader (pp. 65-75). New York: New York University Press.

Marchione, M. (2013, September 19). Weight bias in cancer care? Obese cancer patients often shorted on chemo, hurting survival. Canadian Press. Retrieved from https://www.thecanadianpress.com/news_and_information.aspx?id=1600

Marchione, M. (2014, January 29). "Weight fate' starts early; nearly half of obese 8th graders were overweight in kindergarten. Canadian Press. Retrieved from https://www.thecanadianpress.com/news_and_information.aspx?id=1600 
Marshall, S. J., Biddle, S. J., Gorely, T., Cameron, N., \& Murdey, I. (2004). Relationships between media use, body fatness and physical activity in children and youth: a metaanalysis. International journal of obesity, 28(10), 1238-1246.

Matheson, K. (2014, January 29). Group aims to fight obesity by making healthy food more available at corner stores in Philly. Canadian Press. Retrieved from https://www.thecanadianpress.com/news_and_information.aspx?id=1600

McEwan, M. (2013, November 22). On Visibility. Shakesville. Retrieved from http://www.shakesville.com/2013/11/on-visibility.html

Melius, J. (2013). Overweight and obesity in minority children and implications for family and community social work. Social Work in Public Health, 28(1-2), 119-128.

Mik-Meyer, N. (2010). Putting the right face on a wrong body: An initial interpretation of fat identities in social work organizations. Qualitative Social Work, 9(3), 385-405.

Miller, S. (2012). It begins with food: Food as inspiration and imperative for social change. In L. Samuelson \& W. Anthony (Eds.), Power and Resistance: Critical thinking about Canadian social issues. Fernwood Publishing: Halifax.

Mouawad \& White. (2013, December 23). Airlines squeezing in even more seating. The Boston Globe. Retrieved from http://www.bostonglobe.com/business/2013/12/23/skirmish-forspace-planes-makes-for-even-tighter-squeeze-smallerseats/MDsspXtK6OW0BjdaLrhT8H/story.html 
Mullaly, B. (2002). Challenging Oppression: A critical social work approach. Oxford University Press.

Myers, A., \& Rosen, J. C. (1999). Obesity stigmatization and coping: Relation to mental health symptoms, body image, and self-esteem. International Journal of Obesity and Related Metabolic Disorders : Journal of the International Association for the Study of Obesity, 23(3), 221-230.

NAAFA Policies: Weight-Loss Drugs. (n.d.). National Association to Advance Fat Acceptance. Retrieved from http://www.naafaonline.com/dev2/about/Policies/WEIGHTLOsSDRUGS.pdf

NAAFA Policies: Weight-Loss Surgery (n.d.). National Association to Advance Fat Acceptance. Retrieved from http://www.naafaonline.com/dev2/about/Policies/WEIGHTLOSSSURGERY.pdf

Neergaard, L. (2013, May 28). HEALTHBEAT: Babies born after mom's obesity surgery fare better; genes behave differently. Canadian Press. Retrieved from https://www.thecanadianpress.com/news_and_information.aspx?id=1600

Obese Frenchman stranded for weeks ends travel ordeal after overnight ambulance home. (2013, November 21). Canadian Press. Retrieved from https://www.thecanadianpress.com/news_and_information.aspx?id=1600

Owen, L. J. (2008). Living Large in a Size Medium World: Performing Fat, Stigmatized Bodies and Discourses. ProQuest. 
Parsons, M. (2012). Fat Phobia and the Politics of Gender. In L. Samuelson \& W. Anthony (Eds.), Power and Resistance: Critical thinking about Canadian social issues. Fernwood Publishing: Halifax.

Philips, N. and Hardy, C. (2002). Discourse Analysis: Investigating Processes of Social Construction. London: Sage.

Poole, J. M. (2007). Behind the rhetoric of hope: A critical analysis of recovery discourses in Ontario. ProQuest.

Poulton, T. (1996). No fat chicks: How women are brainwashed to hate their bodies and spend their money. Toronto: Key Porter Books.

Robertson, A. (1998). Shifting discourses on health in Canada: From health promotion to population health. Health Promotion International, 13(2): 155-166.

Robinson, B. E., Bacon, J. G., \& O'Reilly, J. (1993). Fat phobia: Measuring, understanding, and changing anti-fat attitudes. The International Journal of Eating Disorders, 14(4), 467-480.

Rothblum, E. D., Brand, P. A., Miller, C. T., \& Oetjen, H. A. (1990). The relationship between obesity, employment discrimination, and employment-related victimization. Journal of Vocational Behavior, 37(3), 251-266.

Sagapolutele, F. \& Perry, N. (2013, April 3). Samoa airline starts pay-by-weight pricing for international flights. Canadian Press. Retrieved from https://www.thecanadianpress.com/news_and_information.aspx?id=1600

Schiffrin, D., Tannen, D., \& Hamilton, H. E. (Eds.). (2008). The handbook of discourse analysis. 
John Wiley \& Sons.

Schwartz, M. B., Chambliss, H. O., Brownell, K. D., Blair, S. N., \& Billington, C. (2003). Weight bias among health professionals specializing in obesity. Obesity Research, 11(9), 1033-1039.

Schweik, S. M. (2009). The ugly laws: Disability in public. New York; London: New York University Press.

Sealy, Y. M. (2010). Parents' perceptions of food availability: Implications for childhood obesity. Social Work in Health Care, 49(6), 565-580.

Sherry, M. (2004). Overlaps and contradictions between queer theory and disability studies. Disability \& Society, 19(7), 769-783.

Social Work. (2010) Ontario Bariatric Network. Retrieved from http://www.ontariobariatricnetwork.ca/social-work-screening.aspx

Social Workers and their role in decreasing obesity. (n.d.). University of New England. Retrieved from http://socialwork.une.edu/resources/news/social-workers-and-their-role-in-decreasingobesity-rates/

Solovay, S. (2000). Tipping the scales of justice. Prometheus Books.

Stein, M. T. (2011). Media's effect on obesity in kids. Journal Watch Pediatrics \& Adolescent Medicine.

Stobbe, M. (2013, August 6). Childhood obesity fell at least slightly in 18 states; report seen as 
sign of a national drop. Canadian Press. Retrieved from https://www.thecanadianpress.com/news_and_information.aspx?id=1600

Stobbe, M. (2013, November 13). Doctors are told to get tougher with patients about their weight, recommend counselling. Canadian Press. Retrieved from https://www.thecanadianpress.com/news_and_information.aspx?id=1600

Stubblefield, A. (2007). "Beyond the pale": Tainted whiteness, cognitive disability, and eugenic sterilization. Hypatia, 22(2), 162-181.

Superville, D. (2014, March 14). Michelle Obama wants to help more people cook at home, says it saves money, is healthy option. Canadian Press. Retrieved from https://www.thecanadianpress.com/news_and_information.aspx?id=1600

Tanner, L. (2013, June 4). Stomach-stapling treats diabetes in mildly obese but risks must be weighed: study. Canadian Press. Retrieved from https://www.thecanadianpress.com/news_and_information.aspx?id=1600

Tanner, L. (2013, November 4). Major health woes seen in teens who seek obesity surgery; manykids are 3 times too big. Canadian Press. Retrieved from https://www.thecanadianpress.com/news_and_information.aspx?id=1600

Titscher, S., Meyer, M., Wodak, R. and Vetter, E. (2005). Methods of Text and Discourse Analysis. London: Sage.

The Canadian Press: Canada's trusted news leader. (n.d.) Retrieved from http://www.thecanadianpress.com/home.aspx? $\mathrm{ID}=60$ 
Ubelacker, S. (2013, December 2). Benign obesity a myth, even if blood pressure, cholesterol 'healthy,' study says. Canadian Press. Retrieved from https://www.thecanadianpress.com/news_and_information.aspx?id=1600

Vandewater, E. A., Shim, M. S., \& Caplovitz, A. G. (2004). Linking obesity and activity level with children's television and video game use. Journal of adolescence, 27(1), 71-85.

Wann, M. (2009). Foreward: Fat studies: An invitation to revolution. In E. Rothblum and S. Solovay (Eds.), The fat studies reader (pp. ix-xxv). New York: New York University Press.

Yang, C., \& Southwell, B. G. (2004). Dangerous disease, dangerous women: Health, anxiety and advertising in shanghai from 1928 to 1937. Critical Public Health, 14(2), 149-156. 